\title{
Guglielmo Marconi, Augusto Righi and the invention of wireless telegraphy
}

\author{
Matteo Leone ${ }^{1,3,5, a_{(D}}$ and Nadia Robotti ${ }^{2,4,5}$ \\ 1 Department of Philosophy and Educational Sciences, University of Turin, Via Gaudenzio Ferrari 9, 10124 Turin, Italy \\ 2 Department of Physics, University of Genova, Via Dodecaneso 33, 16146 Genova, Italy \\ 3 INFN Section of Turin, Via Pietro Giuria 1, 10125 Turin, Italy \\ ${ }^{4}$ INFN Section of Genova, Via Dodecaneso 33, 16146 Genova, Italy \\ ${ }^{5}$ Centro Fermi, Museo Storico della Fisica e Centro Studi e Ricerche "Enrico Fermi", Piazza del Viminale 1, 00184 Rome, \\ Italy
}

Received 28 January 2021 / Accepted 30 June 2021 / Published online 28 July 2021

(C) The Author(s) 2021

\begin{abstract}
One of the major accomplishments of the late nineteenth-century applied physics was, as it is well known, the development of wireless telegraphy by Guglielmo Marconi, future Nobel laureate. In this paper, we will explore what scientific debt, if any, Marconi had toward another Italian physicist, internationally well known for his research on electromagnetic waves: Augusto Righi. This question will be pursued through a close analysis of Marconi's first patent, of Righi's scientific correspondence and of the specialized and popular press of the time. At the end of this analysis, which includes a brief survey of Marconi and Righi's activity as senators of the Kingdom of Italy, we will better appreciate what Marconi took from contemporary scientists, what specific contributions he is responsible for and, ultimately, what Marconi and Righi thought of each other.
\end{abstract}

Rays of light will not pierce through a wall, nor, as we know only too well, through a London fog. But the electrical vibrations of a yard or more in wave-length [...] will easily pierce such mediums, which to them will be transparent. Here, then, is revealed the bewildering possibility of telegraphy without wires, posts, cables, or any of our present costly appliances. Granted a few reasonable postulates, the whole thing comes well within the realms of possible fulfilment.

William Crookes, "Some possibilities of electricity", The Fortnightly Review 302 (February 1, 1892), 173-181; 174.

\section{Introduction: One mile away}

One of the major accomplishments of the late nineteenth century applied physics was, as it is well known, the development of wireless telegraphy. The formulation of the electromagnetic theory of light, predicting the existence of radio waves, dates back to 1864 and is due to Cambridge physicist James Clerk Maxwell. In late 1870s to early 1880s, a number of "Maxwellian" physicists, such as Oliver Lodge and George Francis FitzGerald, wondered if it was possible to actually produce electromagnetic waves. And, in 1888, German physicist Heinrich Hertz successfully "endeavored to prove by experiment that electromagnetic actions are propagated through air with finite velocity" (Hertz 1888/1893).

Then, a few years later, something apparently unexpected occurred in Bologna, Italy. In 1895, Guglielmo Marconi (1874-1937), a formerly unknown youngster who "never studied physics or electrotechnics in the regular manner," though "deeply interested in those subjects," started doing tests and experiments at his home, near Bologna, "with the object of determining whether it would be possible by means of Hertzian waves to transmit to a distance telegraphic signs and symbols without the aid of connecting wires" [52]. This was Marconi himself speaking, on the occasion of the Nobel lecture he delivered fourteen years later, at the time of the presentation of the Nobel Prize in Physics (jointly awarded to Marconi and Karl Ferdinand Braun) "in recognition of their contributions to the development of wireless telegraphy"!

We wrote above that something unexpected occurred in Bologna. More precisely, as it might be deduced from the Nobel lecture excerpt, we should have written that something occurred near Bologna, in Marconi's home at Villa

\footnotetext{
a e-mail: matteo.leone@unito.it (corresponding author)
} 
Griffone in the hamlet of Pontecchio (now within the municipality of Sasso Marconi, a few miles south-southwest of Bologna). What might contribute to render Marconi's accomplishment a bit less unexpected, is that in those years the chair of Physics at the University of Bologna was held by Augusto Righi (1850-1920) [8,24,25,42], one of leading world expert on the theory of electromagnetic waves, whose 100th anniversary of his death has recently been celebrated. At the time of Marconi's first tests, Righi had been experimentally studying the optical properties of electromagnetic waves for a couple of years now, coming to fully demonstrate the optical properties of these waves and therefore to endorse beyond any doubt Maxwell's theory on the electromagnetic nature of light. These researches were generally considered so fundamental to wireless telegraphy that, when in 1903 Righi's monograph on wireless telegraphy La telegrafia senza filo was published [76], ${ }^{1}$ a book review in the prestigious Nature journal stated in no uncertain terms that "Prof. Righi has considerable claims to be regarded as the father of practical wireless telegraphy" [57, p. 582]. ${ }^{2}$

And, a fortiori, one might wonder if it is a mere coincidence that Righi's summer villa was in Sabbiuno di Montagna, a small hamlet on the other side of the Reno river, just one mile away, as the crow flies, from Villa Griffone! As reported by many Marconi's biographers, Marconi was helped, in his first experiments at Villa Griffone, by Antonio Marchi, an illiterate farmer who was an attendant on the estate. Reportedly, Marchi told his son stories of the days when he had helped the scientist and, notably, told that "one of Marchi's responsabilities [...] was to 'accompany every day the young gentleman to take his lessons from Professor Augusto Righi' and to lead the donkey on which Guglielmo rode" [40, p. 28]. The same, second-hand, recollection had been formerly told by the first Marconi's biographer, Orrin Elmer Dunlap, in a first draft of his book Marconi, the man and his wireless (which was published in April 1937, i.e. just three months before Marconi's death) [28]. It is unclear whether a kernel of truth is concealed within this story or not. In fact, Marconi explicitly stated in his corrections of proofs of Dunlap's biography that "the story of the donkey is mere fiction" [54]. Interestingly, on the same page of the book, Marconi left uncorrected Dunlap's statement that Marconi "enjoyed riding horseback over the hilly country and visiting neighbors" [28, p. 24].

In his Nobel lecture, Marconi was unequivocal as far as possible influences of contemporary scholars - and Righi, in particular - on the origins of his research program:

[Though] I never studied physics [...] I did, however, attend one course of lectures on physics under the late Professor Rosa ${ }^{3}$ at Livorno, and I was, I think I might say, fairly well acquainted with the publications of that time dealing with scientific subjects including the works of Hertz, Branly, and Righi [52, p. 196].

Later, in his proofs correction of Dunlap's book, Marconi reiterated in similar terms on his (lack of) education background: "I have never been a student of the Bologna or of any other University" [54].

It is beyond doubt that Marconi lacked in formal studies. This, not secondary, detail escaped many commentators of the time, including the aforementioned reviewer of Righi's book [76], who, in his review wrote that "it was from [Righi] that Marconi, as a student at Bologna, derived the knowledge of modern electricity which has enabled him to cross the gap which separates the Old World from the New" [57, p. 582]. ${ }^{4}$ Marconi's lack of formal studies is supported by what Righi repeatedly wrote at the times of Marconi's exploit in 1897. In May of that year, Righi told to a newspaper reporter in Bologna (from the Il Resto del Carlino daily newspaper) that "Marconi is not one of my pupils, and I am sorry of that, indeed he was never a university student." According to Righi, "I soon realized his excellent experimental aptitudes and given the ardor with which he devoted himself to studies and physical tests, I repeatedly advised him to prepare for the high school license exam in order to then be able to regularly attend university courses" [30]. In a letter to Oliver Lodge, dated June 18, 1897, Righi wrote that "I know this young man, who is very intelligent although but little instructed in Physics. I have advised him to pursue a regular University Course" [69]. And, on June 25, Righi wrote again to Lodge that "the young Marconi

1 Righi's book was also released simultaneously in Germany [77]. An enlarged second edition was later published in Italy [76], Germany [77] and Spain [78].

2 As it was observed by the reviewer, "while the book has been specially drawn up for the general reader, there are few physicists who can read it without learning something new about the history of the series of inventions and discoveries which have culminated in Transatlantic Marconigraphy."

3 Vincenzo Rosa (1848-1908) was a high school physics teacher who gave private lessons to Marconi, under his mother's, Annie Jameson, arrangement. In an interview, published on July 4, 1897, when asked "Did you study physics at Bologna under Prof Righi?", Marconi had answered in very similar terms: "I studied under the renowned Professor Vincenzo Rosa at the Livorno Lyceum and would be most happy that it be known that he was my only physics master." (excerpt of translation published on La Tribuna, July 4, 1897, from Jolly [40, p. 16-17]).

4 From this erroneous premise, the reviewer also came to educational policy conclusions: "The benefits that the university and its professor have conferred on mankind by training a Marconi suggest the question: Should not universities be endowed with exceptional scholarships to assist exceptional men? The advantages of expending 100l. annually to help on students of average mediocrity are well known. On the other hand if a university should produce a man with the enterprise of Marconi once in 100 years, the advantage to the community of enabling him to carry on his experiments with the accumulated amount of an annuity that has been left unawarded during the interval cannot be overestimated" [57, p. 582]. 
has a strong desire to become an inventor. On several occasions, he has questioned me on ideas and inventions that, though ingenious, would be difficult to realise. I have advised him to undertake formal studies and to follow a university course" [70].

It is also beyond doubt that, as outlined in his Nobel lecture, Marconi was aware of Righi's works. At the festivities held in Bologna in early October 1902 on the occasion of Marconi's return to his native town, Marconi stated indeed that Righi "made great studies on electric waves, and the result of his profound studies has greatly benefited my discoveries" [55]. And, at the time of Righi's death in 1920, Marconi reiterated that "although I never had, as is often stated, the privilege of being a pupil of Prof. Righi, I have always had, as is well known, a very deep admiration for him and for his great and far-reaching work in connection with physics and particularly electric waves" [53].

It is very likely that Marconi actually visited Righi both at his summer estate in Sabbiuno di Montagna and at his laboratory at the University of Bologna. Furthermore, Marconi also likely exploited the library at the Institute of Physics ([26], p. 62; [27], p. 17). In 1903, when it was published his book about wireless telegraphy [76], Righi pointed out that Marconi, in his villa in Pontecchio, spent his days "trying and trying again," as if "burned with a fever to invent or discover something." As recollected by Righi, "I was vacationing not far away, on the other side of the Reno river: and during the summer he came several times to see me. In the winter, then, he would visit me in [my] cabinet [at the University of Bologna], where he entertained me with his numerous projects, or attended some of my experiences with keen interest" [20]. And, a brief news published on Nature in 1902 reported Righi saying that "I remember with great pleasure his visits when quite a young man, for asking my advice, for explaining his experiments, made with simple apparatus ingeniously put together, and for keeping me informed of his new projects, in which his passion for applied sciences always stood out. Even then I predicted that he would sooner or later attain fame" (Notes. Nature 66 (1902): 583). A testimony on Marconi's visits to Righi's laboratory, came from Bernardo Dessau, who was Righi's assistant in Bologna during the 1890s. During a conference delivered by him in 1907, Dessau recollected that Righi's research "had a result of supreme practical importance, the possibility of which was revealed to the ingenious intuition of the young Marconi, when, myself present, he had the opportunity to know the instruments Righi had devised and the purposes for which they were to serve" [22].

As to the topics addressed during those visits, though we are on a very uncertain ground, we can safely assume that Righi did not advise him on topics directly concerning wireless telegraphy. On the one hand, in his corrections to Dunlap's proofs, Marconi pointed out that "I was not a pupil of Professor Righi and never discussed electric waves with him before I had gained a world-wide reputation" [54]. On the other hand, as Righi wrote to Lodge in 1897, "Mr. Marconi has seen my experiments and I have given him explanations regarding them. I have not seen him for two years and it is really in this period and unbeknownst to me, that he has developed his alleged invention" [70]. In March 1903, Righi told to a journalist that he was repeatedly qualified as Marconi's master and that he would be "very happy for such a title"; however, "it would be necessary that that word could be given a very broad meaning, to apply it to those who had only conversations with the young inventor, most of the time on projects of experiences or practical applications different from the one that deservedly made it famous, and at most provided him with explanations, clarifications or advice on those projects" [1].

In the following, we will not try to examine the specific question of whether Marconi actually paid visits to Righi on a back of a donkey and will not probe details of what actually occurred during those visits and during Marconi's visits at Righi's laboratory. Due to the scarce available documentation, these are perhaps "undecidable" historiographical problems. Rather, we will cover the more general issue of what scientific debt, if any, Marconi had toward Righi with respect to the invention of wireless telegraphy.

This question is not novel in the historiography of physics. ${ }^{5}$ However, it is here pursued through a close analysis of Marconi's first patent. Furthermore, we have also exploited the specialized and popular press of the time and, most importantly, a number of archival repositories as: the "Fondo Augusto Righi" and the "Matteucci prize" folder at the Italian National Academy of Science "detta dei XL" in Rome (henceforth AXL); Righi's archives at the Department of Physics of the University of Bologna; Marconi's archives at the Bodleian Library in Oxford; the "Archivio Guglielmo Marconi" at the Accademia dei Lincei in Rome; and the Historical Archives of the Senate of the Republic in Rome. The historical archive that proved to be of greatest interest to our research is the "Fondo Augusto Righi" (AXL), where most of Righi's scientific correspondence is there preserved. Other collections of interest proved to be the "Matteucci prize" folder (AXL), where one can get important information about Righi's attitude toward Marconi, the "Archivio Guglielmo Marconi" (Accademia dei Lincei), where some interesting notes about Marconi's formative years are available, and the Historical Archives of the Senate of the Republic in Rome, where we consulted the personal folders and the Atti Parlamentari concerning Marconi's and Righi's activities, that partly took place in the same years, as senators of the Kingdom of Italy.

5 A number of Marconi's personal and scientific biographies, covering also his early years in Italy, exist (e.g., [28,37,38,40, $56,62,100])$. On Marconi's formative years see also [29,99]. On Marconi's scientific biography see also the introduction to Bibliografia marconiana [23, pp. 3-12] and the proceedings of the celebrations for the 100th anniversary of Marconi's birth [63]. 


\section{The invention of wireless telegraphy: from Bologna to England}

The story of the invention of wireless telegraphy is pretty well known, though it is still matter of historiographical debates. Controversies about such an invention date back to the late 1800s, when they opposed, on one side Marconi himself and a number of influential non-scientists mainly interested in a practical approach to wireless communication, e.g. William H. Preece, chief engineer of the British General Post Office, and on the other side the above mentioned "Maxwellians" (e.g. Lodge), professional and academic physicists much more interested in Maxwell theory and in specific experimental topics concerning electromagnetic waves than in the communication problem as such.

According to the standard view, eventually accepted by the scientific community at large and, notably, by the Swedish Academy, though various physicists and technicians had previously investigated whether radio waves could be used to transmit signals, it was Marconi who, in 1895, started using radio waves to transmit signals over a distance of more than two kilometers [89] and, in subsequent years, developed the technology to achieve greater range. If Hertz's discovery "forms the foundation [...] for wireless telegraphy," as told by the President of the Royal Swedish Academy of Sciences in his award ceremony speech for the Nobel prize, "a man was needed who was able to grasp the potentialities of the enterprise and who could overcome all the various difficulties which stood in the way of the practical realization of the idea. The carrying out of this great task was reserved for Guglielmo Marconi" [35].

As it is well known, after his first successes in Italy in the transmission of wireless messages and after an unsuccessful attempt to interest the Italian Ministry of Posts and Telegraphs, in early 1896 Marconi moved to England to continue his experiments and eventually gained the interest and support of the British engineer Preece. After his public transmission of July 27, 1896, when wireless signals were sent between two Post Office buildings in central London, Marconi succeeded in interesting the British authorities. A pivotal moment occurred on September 22, 1896, when Preece reported to the annual meeting in Liverpool of the British Association for the Advancement of Science that "a young Italian, Signor Marconi, described to him experiments in which he had, by means of Hertzian waves, transmitted signals to a great distance." As reported by The Times on the following day, Marconi, with Preece's assistance, "had continued his experiments in London and on Salisbury plain he had succeeded in producing electric waves and reflecting them from one parabolic mirror to another one a quarter mile distant. At the latter place they fell on a receiving apparatus, which actuated a relay and produced Morse signals" [90].

News about Marconi's accomplishments was bounced by the Italian press on December 22, 1896, when the Bologna newspaper Il Resto del Carlino reported about a public lecture delivered some days before at the Toynbee Hall, where Marconi "achieved great success with his device and the audience cheered loudly" [39]. One month later, British physicist Silvanus Phillips Thompson wrote to Righi as follows (Fig. 1):

Can you tell me who is this young M. Marconi, who has recently come to London with an apparatus for telegraphy by means of electric waves? I hear that he comes from Bologna. Is he one of your students? What is it that he has discovered, and in what way does his principle differ from that of the apparatus with which you, and Hertz, and Lodge have worked? There is much mystery observed in London about him [91].

Three months later, in March 1897, London's Strand Magazine featured "an interview with Signor Marconi" that, although lacking in technical details, was destined to cause a sensation. In the interview, Marconi explained how he has been, for ten years, "an ardent amateur student of electricity" and, "for two years or more," he has been working with electric waves on his father's estate. Marconi told to the journalist that "in September of last year," while using "the Hertz waves from an apparatus, which you may photograph, a modified form of the apparatus for exciting electric waves, as used by Hertz," in order to "determine how far these waves would travel in the air for signaling purposes," he discovered that he got signals "at distances of a mile or thereabouts" and that the waves also affected "another receiver which I had set up on the other side of a hill." In other words, "the waves were going through or over the hill" [21]!

The interview was accompanied by an iconic photograph showing Marconi sitting behind his apparatus (Fig. 2). With this interview and this photo, Marconi had entered the history of popular science. It won't be long before he hit history at large.

\section{Righi's oscillator versus Marconi's transmitter}

In 1888, Hertz had managed to produce and reveal in the laboratory the electromagnetic waves predicted by Maxwell's theory and to show that those waves, like light, were reflected and refracted, as predicted by Maxwell. Hertz, however, had stopped at these two optical properties of electromagnetic waves only. Soon after, Hertz suspended these studies to devote himself to the discharges in rarefied gases, one of the main research topics in that period. And even those who, immediately after Hertz, became interested in the analogy between light and 


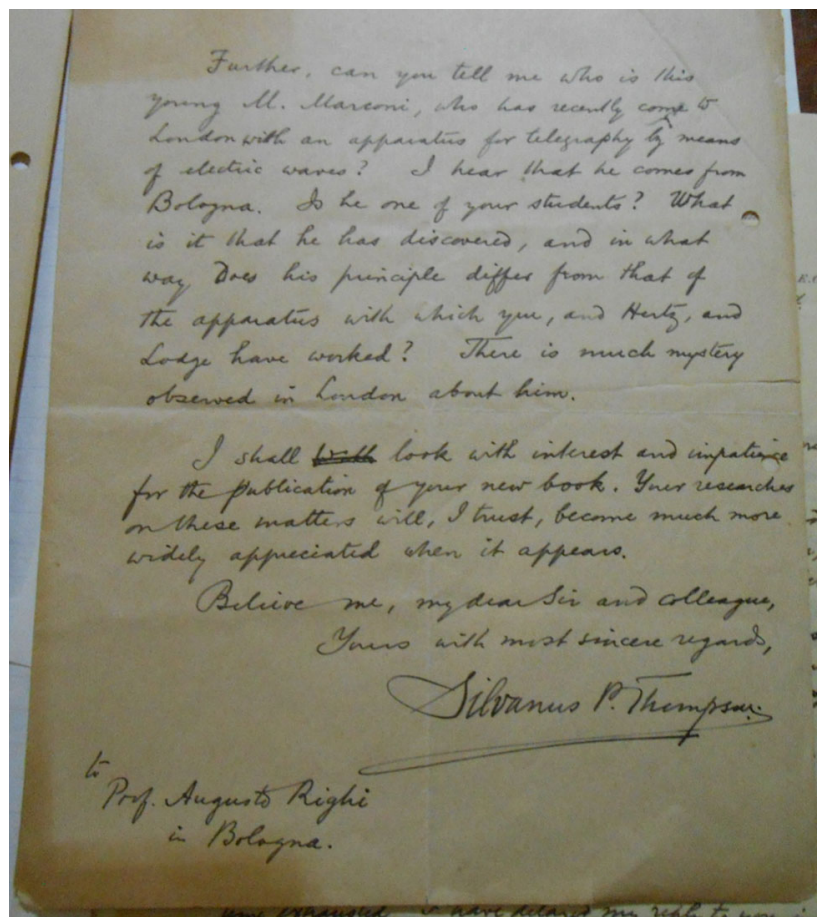

Fig. 1 Silvanus Thompson asking Righi "can you tell me who is this young M. Marconi [...]?" [91]

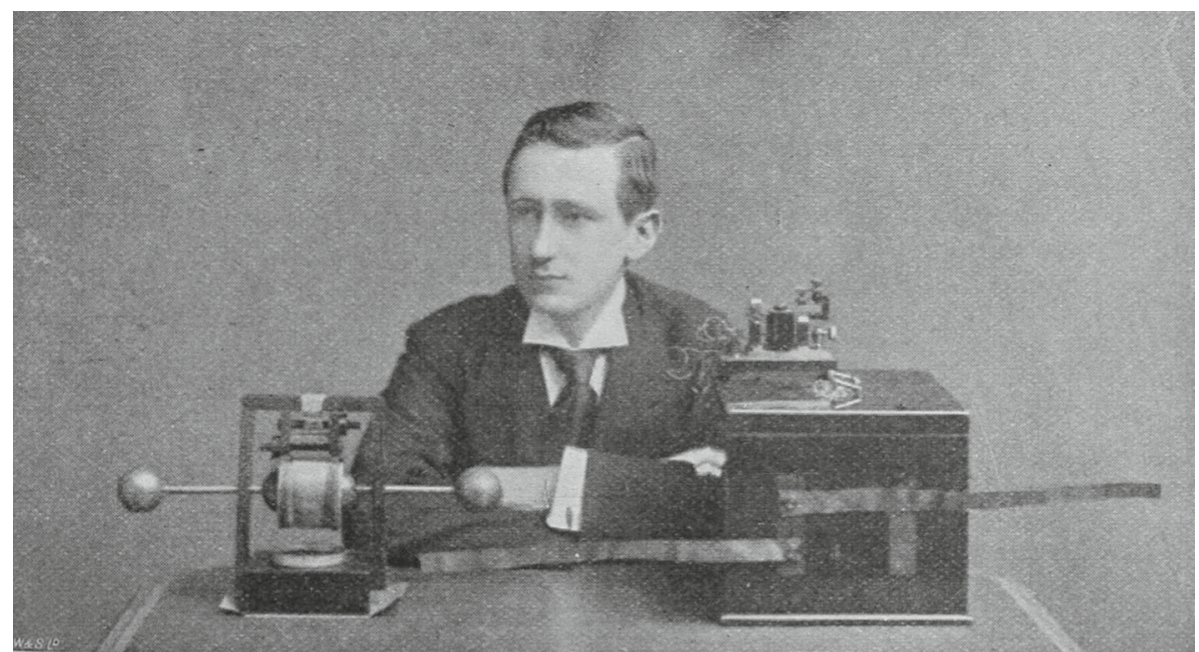

Fig. 2 Marconi with his instruments [21]. At left, one can see Marconi's transmitter. Marconi's receiver is inside the closed box

electromagnetic waves, managed to find only a single new optical property of electromagnetic waves, namely that of being able to be "concentrated by means of a large converging lens" [43].

According to Righi, the reason for these poor progresses lay in the fact that the minimum wavelength obtained by Hertz and his "continuators" was only about $66 \mathrm{~cm}$. "Such a wavelength would in fact oblige to use very large devices, in order to avoid the occurrence of diffraction phenomena that would conceal many of the optical phenomena similar to those usually produced by light waves" [68, p. 488]. Righi was aware that in order to reproduce with Hertzian waves also the other phenomena of optics, and at the same time avoiding those diffraction phenomena which would hide any other optical phenomenon, apparatuses of such large dimensions as to be practically not feasible were required. So, with the aim of giving a solid basis to the electromagnetic theory of light, by demonstrating experimentally that "the analogy between electric vibrations and light vibrations" was "intimate and complete," Righi undertook "to create devices, capable of producing waves somewhat shorter than those given by Hertz devices and suitable for a systematic and complete study of the effects that the waves generated by them can produce" [8, p. 99] (Fig. 3). 


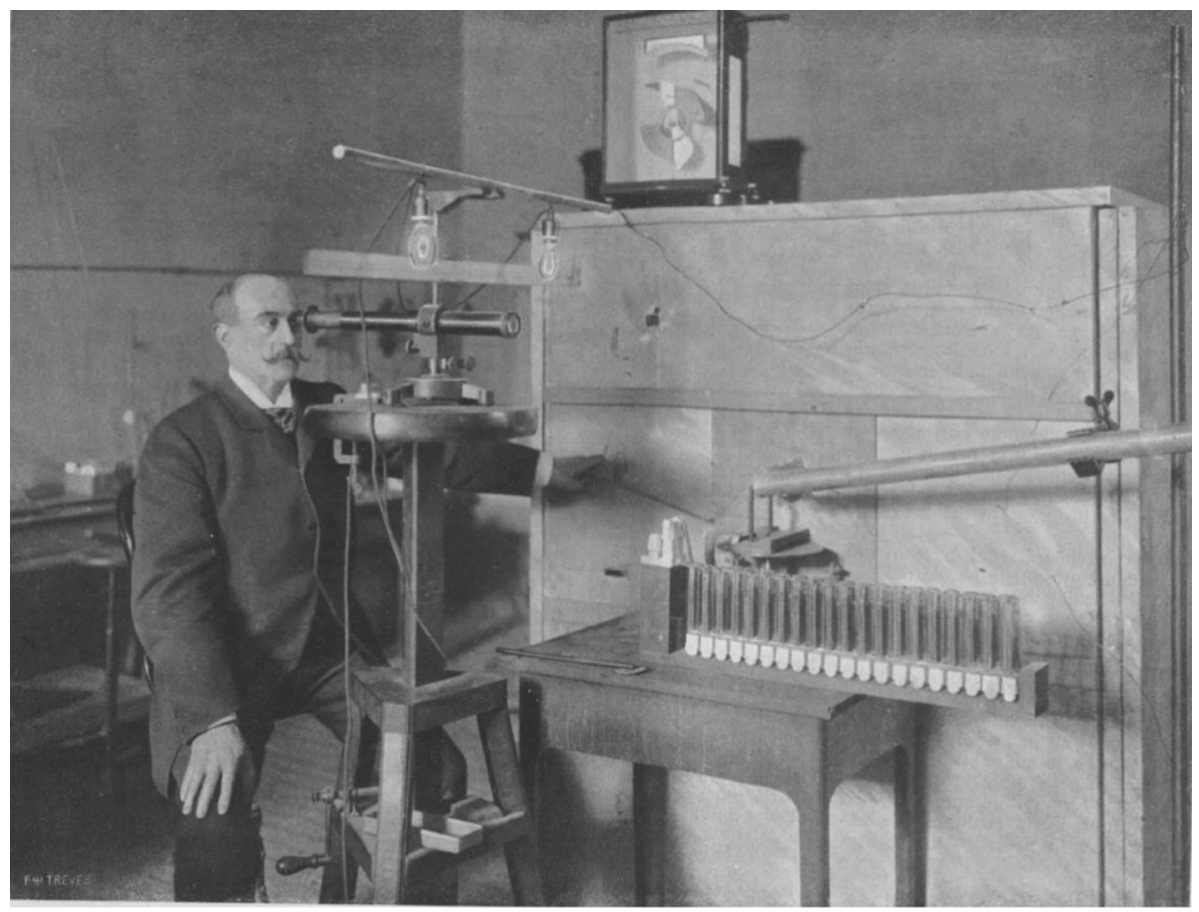

Fig. 3 Righi in his laboratory at the University of Bologna [59, p. 171]

This was precisely Righi's winning idea, which allowed him to achieve the goal he had set himself. In particular, he devoted all his efforts to building oscillators that produced electromagnetic waves of small wavelength and resonators that received electromagnetic waves with the greatest possible sensitivity. He thus came to the realization of his famous, and ingenious, oscillator, dating back to 1893.

Hertz oscillator was nothing more than a capacitor that is repeatedly discharged, through a circuit, in such a way that the discharge is oscillating. As it was well known to Righi, "the period of oscillation increases with the capacitance of the capacitor and the self-induction of the circuit" [68, p. 488]. In Hertz oscillator, the armatures were made up of two metal rods at the ends of which two metal spheres were often placed and the dielectric was none other than the ambient air surrounding the two conductors (Fig. 4). To obtain very short periods of oscillation, it was therefore necessary to decrease the capacity and self-induction. For this purpose, Righi made use of oscillators consisting of two small metal spheres placed close to each other, so that, once charged, they can discharge with a short spark. As Righi understood, however, "the effects that an oscillator of this kind, made up of balls of a few centimeters in diameter, gives are very weak" [68, p. 489].

In order to get at the same time waves of short wavelengths and strong effects, Righi made an oscillator where two electrodes, placed laterally, carried two metal spheres in the middle of which there were two other metal spheres immersed in a container filled with vaseline oil. By dipping the central spheres in the dielectric liquid, Righi obtained an increase of the quantity of charge necessary for the spark in such a way as to compensate for the loss of intensity due to the smallness of the metal spheres. By connecting the electrodes to an induction coil, three sparks (two lateral and one central) strike between the spheres. The central spark, which was produced in the oil, was oscillatory and it was precisely this that generated the centimeter electromagnetic waves. With spheres of $8 \mathrm{~cm}$ in diameter, Righi was able to produce waves with a wavelength of $20 \mathrm{~cm}$, while with spheres of $3.75 \mathrm{~cm}$ in diameter he was able to obtain wavelengths of $10.6 \mathrm{~cm}$ (with another smaller type of oscillator the wavelength even dropped to $26 \mathrm{~mm}$ ). The experimental arrangement was such that Righi called his apparatus as "three-spark oscillator" (Fig. 5).

In the May 28, 1897 interview with Il Resto del Carlino, Righi emphasized that "in the figure accompanying [...] Marconi's interview [to Strand Magazine] [Fig. 2], the two conductors can be clearly seen, as well as the drum containing the liquid, quite similar in external form to that of [my] oscillator" [30]. If one compares the left instrument in the Strand Magazine photograph (Fig. 2) with a diagram of Righi's oscillator [67] (Fig. 5), the similarities are striking.

The subsequent exchange between the journalist and Righi is eloquent on the latter's attitude, an attitude that differentiates him, as we shall see, from that of his English friends:

Forgive me, if I interrupt you-the Il Resto del Carlino journalist said-but, from what you tell me, wouldn't the Marconi transmitter be new? 


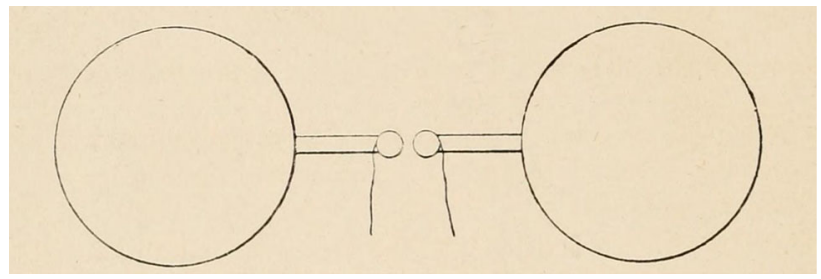

Fig. 4 Diagram of a standard Hertz oscillator [44, p. 8]

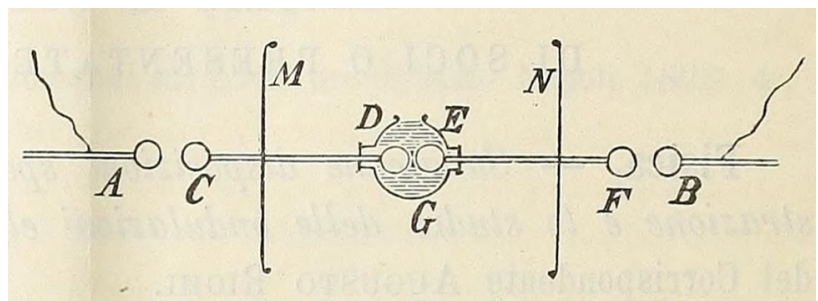

Fig. 5 Diagram of Righi's oscillator [67]

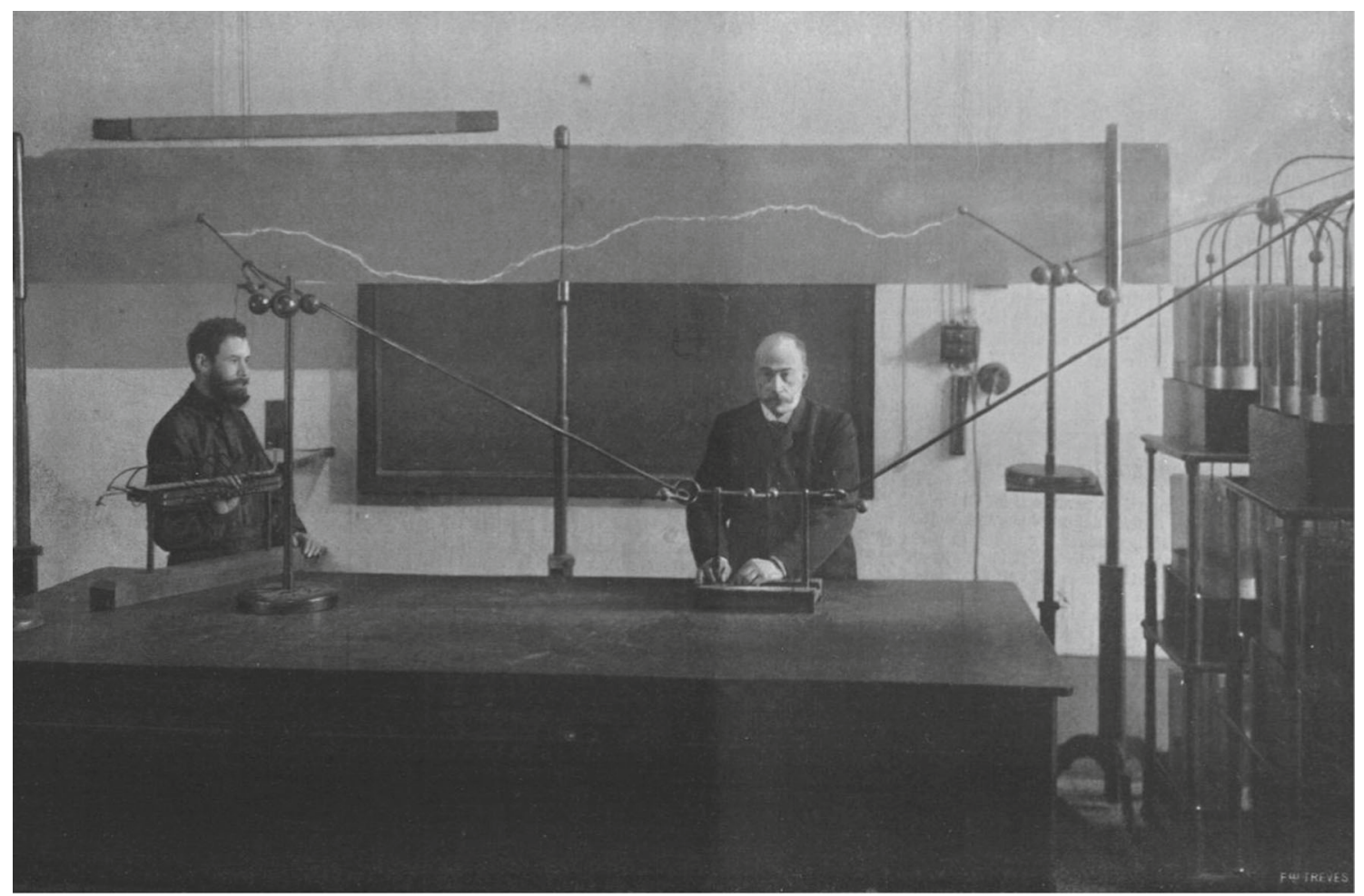

Fig. 6 Augusto Righi (center) and Bernardo Dessau (left) in Righi's laboratory at the University of Bologna. In this photograph, Righi is shown while preparing a class on electromagnetic waves [59, p. 171]

This is how it appears. Of course, only when Marconi has published a description of his devices will it be possible to judge whether and what innovations are contained in them. But I hasten to add that, in my opinion, all this does not detract from Marconi's merit. While I have used my oscillators to produce very short electric waves, with which I have tried to carry out experiments in support of the identity of nature of electric waves and light waves, Marconi, perhaps indulging his own nature which draws him towards the applications of science rather than towards the great questions of natural philosophy, conceived the brilliant idea of making electric waves serve the production of remote signals [30].

The whole set of Righi's experimental results, obtained on electromagnetic waves as early as 1893, were summarized by him in 1897 in his book titled L'ottica delle oscillazioni elettriche (Optics of electric oscillations), soon translated in German [71,74]. Given the spectacular experimental results obtained by Righi, in which electromag- 


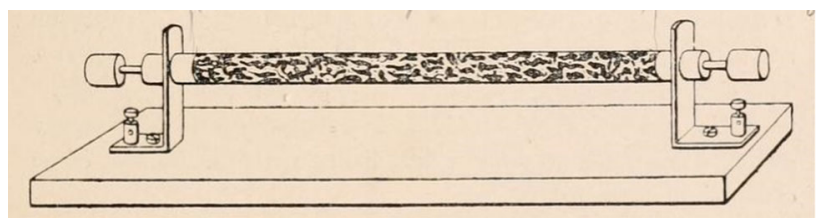

Fig. 7 Lodge's coherer [44, p. 23]

netic waves were made to travel in space "even at a distance of 25 meters" [67, p. 337] (i.e. a length corresponding to that of the longest corridors of Palazzo Poggi, which at the time housed the Institute of Physics of Bologna), it is natural to assume that Marconi, while witnessing to these tests, was much impressed by them to the point of embracing the great idea of transmitting with these waves a Morse signal over long distances. This was also the thought of Righi who, in an undated note, wrote about Marconi: "The fact is that the idea of wireless telegraphy came to him after I showed him and made him understand my experiences on electric waves" (this undated note is reproduced in Dragoni [25], p. 62) (Fig. 6).

\section{Marconi's "closed box" (and Righi trying to open it)}

Righi, in his 1893-1894 experiments on the "optics of electric oscillations," had used an improved version of Hertz's "resonator" in order to obtain greater sensitivity. Hertz resonator usually consisted of an open metallic ring terminating with two metallic spheres: an electromagnetic wave produced by an oscillator would induce a current through the ring, an accumulation of charges in the spheres and a discharge in the breakpoint.

Righi's "resonator" was instead made of a layer of silver with a thin incision (0.002 $\mathrm{mm}$ in thickness) across its center, which acted as a dipole antenna. As Righi wrote in 1894, "when a resonator is exposed to the radiation of the oscillator, first holding it at a very great distance and then gradually bringing it closer, sparks appear at a certain instant ... it is just like a row of very bright green stars" [68, p. 497]. By a suitable choice of dimensions of resonator and oscillator, he was able to obtain, as aforementioned, an "effect still clearly visible when the two devices are ... at a distance of 25 meters" [68, p. 501]. At that time, he reasoned in terms of observing an effect in his resonator and not in terms of transmitting a signal over a distance. However, as he later wrote in his book on wireless telegraphy, this experience "always surprises those who witness it for the first time, and it is natural that it spontaneously gave rise to the idea of translating it on a large scale for the production of remote signals" [76, p. 179].

Marconi's "receiving instrument," however, was of a different conception compared to Hertz's or Righi's resonator. Righi, in his May 28, 1897 interview, wondered if Marconi's receiving instrument was just a "coherer," that is the instrument devised by Lodge in 1894 [88] and based on the discovery, due to Edouard Branly, that copper filings in a glass tube conducted feebly under ordinary conditions, but that their conductivity increased abruptly when a spark was generated nearby (Fig. 7):

The figure shown in [Strand Magazine] [Fig. 2], in which Marconi is portrayed with the instruments he uses in front of him, shows a closed box with external appendages near the oscillator. Although these appear to constitute a resonator [...], nothing can be guessed as to how it works. But I can tell you [...] that [we] already know a device which [...] can reveal the existence of electromagnetic waves, even if very weak, or coming from a very distant oscillator. This apparatus, based on certain ancient observations by Du-Moncel and in particular by another French physicist, Branly, is the invention of Lodge [...] [30].

Righi even came up with a small experimental demonstration of how the coherer works for the benefit of the journalist.

I take a glass tube, closed at one end with a cork stopper crossed by a copper wire, I fill it with this iron filings that I got from my mechanic, and then I close it with a second stopper which is also crossed by a metal wire. I join the two wires to the poles of this battery, [...] but I include in the circuit the wire of this instrument, which is a galvanometer.

You see in the galvanometer a small, delicately suspended magnetized needle, which is naturally oriented approximately north to south. As soon as the electric current passes through the circuit, the needle changes direction, or as they say, deviates. However, although the powder that fills the tube is metallic, the current encounters such resistance to the passage from one filing particle to another, that it remains so weakened that the needle is not significantly displaced. Now, please watch it closely as I go down there to run my oscillator. As you see, at the first spark the needle deflected and remained in the new position. The waves generated by the spark instantly reduce the resistance $[. .$.$] to the passage of the current between the grains of iron.$ 
As you see, just a slight blow on the tube is enough for the galvanometer needle to return to its original position, and the tube becomes capable of revealing a new spark produced in the distant oscillator. Moreover, the necessary tap can be produced automatically [30].

As we will see, the automatic tapping of the receiver will be a subject of much controversy between Marconi and his English opponents. Anyhow, Righi concluded that, since Marconi's box is closed, he doesn't know by sure if Marconi's receiver is or is not a Lodge's coherer, "but it seems to me probable that the Lodge device could very well serve the same purpose, either as it is or with some slight modification."

\section{Marconi and Preece at the Royal Institution}

A few days after Righi's interview, a much influential public lecture about the "Marconi system" was delivered in London. On June 4, 1897, before a crowded audience at the Royal Institution, Preece lectured on "Signalling through space without wires." As reported in detail by The Times a few days later,

Last July [1896] a young Italian brought a new system to England, in which Hertzian waves of very high frequency were utilized. [...] The transmitter was Righi's form of Hertz radiator, consisting of two spheres of solid brass, $4 \mathrm{~cm}$ in diameter, fixed in an insulated case filled with oil, in such a way that a hemisphere of each was exposed, the other hemisphere being immersed in the oil. The oil kept the surfaces of the spheres electrically clean, it impressed on the waves excited a uniform and constant form, and it tended to reduce the wave-length. Mr. Marconi generally used waves about 120 centimetres long. The radiator was excited by an induction coil, controlled by a Morse key. A 6-inches spark coil had sufficed for distances up to four miles, but for greater distances a larger coil had to be used. The receiver consisted of a small glass tube four centimetres long into which two silver pole pieces tightly fitted, the half-millimetre space between them being filled with a mixture of fine nickel and silver filings mixed with a trace of mercury. The tube, which was exhausted to a vacuum of $4 \mathrm{~mm}$, formed part of a circuit containing a local cell and a sensitive telegraph relay. In its normal condition this metallic powder was virtually an insulator, but when electric waves fell on the particles they were marshalled and arranged in such a way that they became a conductor. Hence a current passed which could be used to ring a bell or indicate a signal in other ways. But in order to apply this device to practical work it was necessary to have some means of again rendering the filings non-conductive, and this Marconi managed by making the local current vibrate a small hammer-head against the glass tube, thus shaking the filings back into an insulating condition [83].

By this method, signals had been transmitted across the Bristol Channel, a distance of nearly 9 miles. "It was curious - Preece concluded - that hills and apparent obstructions failed to obstruct the effects, nor did weather seem to have any influence."

Details about Preece's lecture were published on the June 17 issue of Nature journal [84] and, eventually, in Science journal [85]. The description of Marconi's apparatus supported Righi's above conjectures and provided ammunition to Marconi's opponents. In this regard, in his June 18, 1897 letter to Lodge, written before having read the detailed Nature report, Righi wondered: "I shall be very curious to know about his apparatus, but I suspect it much resembles what he rigged up here with my oscillator and your coherer" [69].

To strengthen his point, that is that the novelty of Marconi's accomplishment didn't lie in the apparatus but, rather, in the idea of using it for wireless communication, one month after the lecture at the Royal Institution, on July 4, Righi wrote a letter to Il Resto del Carlino. According to Righi, the conjectures that he had previously put forward were completely confirmed.

[In the interview, I stated] that the Marconi transmitter likely was my vaseline oil oscillator, which I have been using for three years now, and repeatedly described in my publications.

Well, Mr. Preece announced in his speech that Marconi transmitter is none other than the Righi oscillator.

As for the receiver, I said in that interview that it was probably the metal powder device of prof. Oliver Lodge of Liverpool, to whom this illustrious physicist has given the name of coherer, either used alone or connected to a Hertz resonator.

Well, Mr. Preece lets us know that this is precisely the Marconi receiver. Only in the latter, the indoor air is rarefied up to about $4 \mathrm{~mm}$, a trace of mercury is added to the metal powder (nickel and silver) [...].

Therefore, the tools that Marconi uses with such skill are well known [...] but this does not at all diminish the merit that rightly belongs to Marconi, namely that of having had the idea of applying those devices to telegraphy without wires. Although that idea was, as they say, in the air, no one before him had tried to translate it into action [71].

In support of his belief that the wireless telegraphy idea was "in the air," as it might be also deduced by William Crookes' astounding forecast quoted at the beginning of this paper, Righi reported also about the experimental 
results (published in early 1895) carried out by Heinrich Rubens together with W. and E. Rathenau, near Potsdam. In their telegraphic system, the electric impulses were transmitted through the water by a transmitter, up to a receiver located a few kilometers away. According to Righi, in the introduction of the article it was said: "... more than one who has been involved in studying the admirable experiences on the rays of electric force, or who has witnessed a demonstration of them, will have come up with the idea that the time in which messages can be transmitted electrically, without using a conductor wire, is not far away." "Apparently, Marconi is about to fulfill this prophecy" were the closing words of Righi's letter.

\section{6 "There is absolutely nothing new in the whole thing"}

British physicists like Lodge or Silvanus Thompson were unconvinced about Marconi's method. Their skeptical attitude was not directed toward the accomplishments reported by Preece, but concerned the originality of Marconi's method and its scientific significance.

"All this is very absurd, because there is absolutely nothing new in the whole thing," Lodge wrote to his friend Righi on June 21, 1897. As reported by Lodge, "your protégé Marconi has obtained the ear of the British Post Office officials, some of whom are like him not well versed in Physics" [46]. The following day, June 22, Lodge wrote a letter to The Times with the goal of putting into perspective the news reported by the chief engineer of the General Post Office before the Royal Institution. Lodge complained that "many persons suppose that the method of signaling across space by means of Hertz waves received by a Branly tube of filings is a new discovery made by Signor Marconi, who had recently been engaged in improving some of the details." However, according to Lodge it was, not only a matter of "details" but, also, a matter of priority:

It is well known to physicists, and perhaps the public may be willing to share the information, that I myself showed what was essentially the same plan of signalling in 1894. My apparatus acted very vigorously across the college quadrangle, a distance of 60 yards, and I estimated that there would be some response up to a limit of half a mile. [...] My apparatus was substantially the same as that now used by Signor Marconi- there was a row of sparking spheres; the sparks were taken under oil sometimes [...]; there were iron and brass filings in a high vacuum and likewise in hydrogen; there was also my own coherer with a single contact, which is more sensitive, but less manageable, than a filings tube; and the restoration to sensitiveness was effected by an electrically-worked hammer. Signor Marconi uses nickel and silver filings in a lower vacuum, and by employing greater power he has obtained signals over much greater distances [47].

For Lodge, Marconi's one does not deserve to be called an important discovery.

The only "important discovery" about the matter was made in 1888 by Hertz; and on that is based the emitter of the waves; the receiver depends on cohesion under electrical influence, which was noticed long ago by Lord Rayleigh and has been re-observed in other forms by other experimenters, including the writer in 1890 [47].

In his June 22, 1897 letter to The Times Lodge, besides erroneously stating that Marconi was "instructed primarily by Professor Righi," observed, not without malice, that Marconi was "aided in his trials by the British Post Office," that "he has worked out hard to develop the method into a commercial success" and that "for all this," rather than for his discovery, "full credit is due." A similar complaint came four days later from a faithful ally of Lodge, the above cited Silvanus Thompson. In his article for The Saturday Review (a London weekly newspaper) on the "Telegraphy without wires," Thompson observed that the first apparatus to transmit electric waves, due to Hertz, "is simply a metallic conductor, divided at the middle to provide a spark-gap" and that "improved forms of the wave-emitter have been devised by Professor Righi of Bologna and by Professor Oliver Lodge of Liverpool, both of whom have labored long and well in developing scientifically the path thus pioneered by Hertz." As to the detectors, "foremost of these is the form used by Lodge," which "depends upon the earlier discovery by Branly." And, as a matter of fact, Marconi "uses a Righi transmitter and a modified Branly detector." Thus, Thompson concluded with the following lines:

It is but nine years since the discoveries of Hertz in this out-of-the-way region of abstract science put into our hands the means of creating electric waves. Hertz died all too soon to see the first-fruits of the germ which he planted. Now after nine years others enter in to reap the benefit of his discoveries, and to create financial schemes for exploiting the product of his brain. Let them not forget to acknowledge that the only real novelties in the whole thing are the Hertz wave and the Branly detector, both of which were given freely and unpatented to the world [92].

So, according to Lodge and Thompson, there was no real novelty in Marconi's system. The Maxwellian physicists had served their sentence without appeal. 


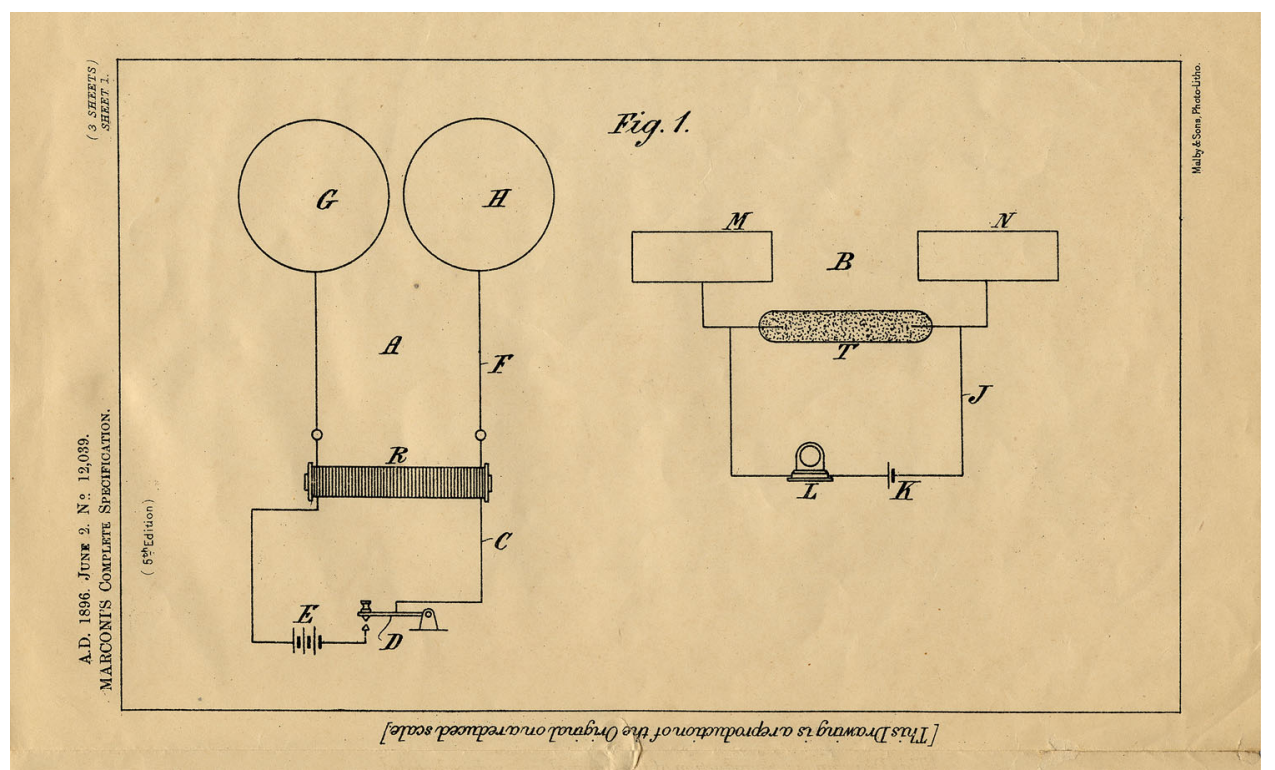

Fig. 8 Diagram showing Marconi's apparatus for transmitting electrical impulses and signals [49, Figure 1]

\section{The UK patent 12039/96}

In his June 21, 1897 letter to Righi, Lodge, besides stressing that there was "absolutely nothing new in the whole thing," added that anyway Marconi "had the sense to take out a patent, and that is a valuable commodity." Also, Lodge attempted to establish an "alliance" with Righi to dispute the patent claim: "I am disposed to contest the novelty when the time is ripe, and maybe glad of your help" [46]. Righi's June 25 reply reveals a magnanimous attitude toward his fellow Italian: "Young as he is, you should not blame him, if he behaved less than courteously to me. He has been badly advised, that's all. His real merit is that of being the first, I believe, to have the idea of using electric waves for signal at distance" [70]. Although Righi shared Lodge's doubts about the patentability of Marconi's apparatus (in his July 4 interview he wrote that since the description of Marconi's transmitter and receiver "was already made public, respectively, by me and Lodge (except perhaps for some changes in the receiver), it seems that everyone is free to build them and to use them for any use, which could damage the possible financial results of a company founded on them"), Righi eventually decided not to pursue legal action against Marconi.

Marconi's UK patent n. 12039/96, titled "Improvements in Transmitting Electrical Impulses and Signals, and in Apparatus therefor," had as date of application June 2, 1896 and date of complete specification was March 2, 1897 [49]. The patent, which was formally granted by the Patent Office on July 2, 1897, followed a provisional specification filed by Marconi on March 5, 1896 (merely containing a crude description of his apparatus and the results obtained by its use), but eventually replaced with the June 2 application. On July 20, 1897, soon after the patent was formally granted, Marconi formed a private company to exploit it, the Wireless Telegraph and Signal Company, whose name was later, in February 1900, changed to Marconi's Wireless Telegraph Company.

A close analysis of the "Complete Specification" of the patent-which begins with Marconi stating that "My invention relates to the transmission of signals by means of electrical oscillations of high frequency" - reveals important details about the method and about its relationships with the contemporary experimental research on electromagnetic waves.

The general schematics of the apparatus was described by Marconi by making reference to Fig. 8, where A is the transmitting instrument and B is the receiving instrument "placed at say 1/4 mile apart."

In A, which is "commonly called a Hertz radiator," we find an ordinary induction coil (R), with the primary circuit (C) connected through a key (D) to a battery (E); the extremities of the secondary circuit (F) are connected to two insulated spheres $(\mathrm{G}$ and $\mathrm{H}$ ) fixed at a small distance apart. As explained by Marconi, "when the current from the battery $\mathrm{E}$ is allowed to pass through the primary of the induction coil, sparks will take place between the spheres G H and in consequence the space all around the spheres suffers a perturbation in consequence of these electrical rays." The effects "which propagate through space [is called] Hertzian rays."

$\mathrm{B}$ - the receiving instrument - consists of a battery circuit $(\mathrm{J})$ including a battery or cell (K), a receiving instrument (L) and a tube (T) containing metallic powder or filings, each end of the column of filings being also connected to plates or conductors ( $\mathrm{M}$ and $\mathrm{N}$ ) of suitable size, "so as to be preferably tuned with the length of wave of the radiation emitted from the transmitting instruments." As pointed out by Marconi, "the tube containing the filings may be replaced by an imperfect electrical contact, such as two unpolished pieces of metal in light contact, or 
coherer etc." To all physicists knowledgeable about Lodge's coherer working, Marconi's description hardly comes as a surprise:

The powder in the tube $\mathrm{T}$ is under ordinary conditions a non conductor of electricity and the current of the cell $\mathrm{K}$ cannot pass through the instrument, but when the receiver is influenced by suitable electrical waves or radiation the powder in the tube $\mathrm{T}$ becomes a conductor (and remains so until the tube is shaken or tapped) and the current passes through the instrument.

By these means electrical waves which are set up in the transmitting apparatus effect the receiving instrument in such a manner that currents are caused to circulate in the circuit $J$ and may be utilized for deflecting a needle which thus responds to the impulse coming from the transmitter [49, p. 3, lines 36-44].

The diagram in Fig. 8 shows the "simple form of apparatus" employed by Marconi in his experiments. In the remaining part of the patent application, Marconi discusses in detail some improvements of that apparatus applicable to the receiving and transmitting instruments, through which

I am able to obtain Morse signals and to work ordinary telegraphic instruments and other apparatus; and with modification of the above apparatus it is possible to transmit signals not only through comparatively small obstacles such as brick walls, trees etc.; but also through or across masses of metal, or hills or mountains, which may intervene between the transmitting and receiving instruments [49, p. 4, lines 31-36].

As regards the receiving instruments, an important improvement consisted in the automatic tapping or disturbing the powder in the sensitive tube, "so that immediately the electrical stimulus from the transmitter has ceased, the tube $[\ldots]$ regains its ordinary non-conductive state." Further improvements consisted in the mode of construction of the sensitive tube, in the prevention of the electrical disturbances which are set up by the trembler and other apparatus in proximity, in the prevention of the high frequency oscillation set up across the plates of the receiver from running round the local battery wires and thereby weakening their effect on the sensitive tube, and in a modified form of the plates connected to the sensitive tube in order to make it possible to mount the receiver in an ordinary circular parabolic reflector. Marconi's patent closes with nineteen claims, mostly concerning such improvements of coherer's setup.

\section{A matter of details: the transmitter}

Marconi explained in his patent application that, for what concerns the transmitting instruments, "my first improvement consists in employing four spheres for producing the electrical oscillations" (Fig. 9). The spheres $d d$ (carried by insulating supports $d^{1} d^{1}$ ) are connected to the terminals of the secondary circuit of the induction coil (as in R, Fig. 8). The sphere ee are two similar balls on supports $e^{1} e^{1}$ whose distance apart can be adjusted by bolts and nuts acting against other nuts. $e^{4}$ is a flexible membrane preferably of parchment paper glued to the supports $e^{1}$ and forming a vessel which is filled with dielectric liquid, preferably vaseline oil slightly thickened with vaseline. As emphasized by Marconi,

The oil or insulating liquid between the spheres ee increases the power of the radiation and also enables one to obtain constant effects, which are not easily obtained if the oil is omitted [49, p. 9, lines 18-20].

The balls $d$ and $e$ are preferably of solid brass or copper and the distance they should be apart "depends on the quantity and electro-motive force of the electricity employed the effect increasing with the distance." In the complete description of his patent application, Marconi describes also a modification of this oscillation producer in which the spheres ee and $d d$ are mounted in an ebonite tube.

Marconi estimated that with an induction giving an ordinary 8 inch spark, the ee distance should be from $1 / 25$ to $1 / 30$ of an inch and the de distance about one inch. Other condition being equal, "the larger the balls the greater is the distance at which it is possible to communicate": Marconi generally used balls of solid brass of 4 inches diameter giving oscillations of $10 \mathrm{in}$. wavelength.

If these conditions are satisfied and with a suitable receiver, a transmitter furnished with spheres of four inches diameter connected to an induction coil giving a 10 inch spark will transmit signals to two miles or more [49, p. 9, lines 39-41].

Marconi explained in his patent application that the oil between the spheres of his transmitting apparatus, preferably vaseline oil slightly thickened with vaseline, was aimed at increasing the power of the radiation and also enabling one to obtain constant effects. All these effects, however, have been known for years.

As above discussed, Righi reported in 1894 that to obtain very short periods of oscillation it is necessary to decrease the capacity and self-induction and that to obtain this the oscillator should use small metal spheres. Although the effects that an oscillator of this kind can give are very weak, these effects "grow enormously by 


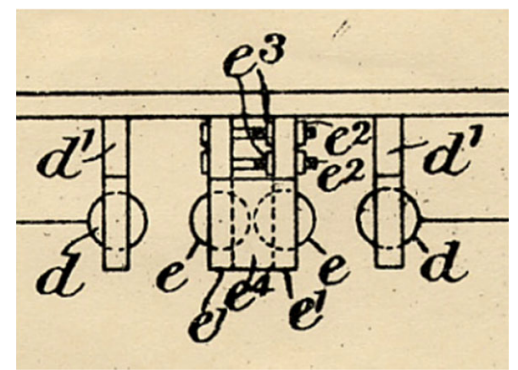

Fig. 9 Particular of the diagram showing the improved Marconi's transmitting instrument with four spheres [49, Figure 3]

resorting to an artifice which consists in triggering the spark that joins the two conductors within an insulating liquid" [68, p. 489]. The discovery of this effect, by the use of olive oil, occurred in 1892 and was due to Auguste De La Rive and Edouard Sarasin [82]. However, as discovered by Righi soon after De La Rive and Sarasin, olive oil was not the best choice.

I just adopted this arrangement, that is, I placed an insulating liquid between the two spheres; but I found vaseline oil to be very preferable to olive oil [...] especially making it poorly flowing by dissolving a sufficient amount of Vaseline [68, p. 489]. [emphasis added]

Righi explained the effectiveness of the liquid in this way: in order to start the discharge between the two conductors, a much higher potential difference must be reached between them when they are separated by the insulating liquid, than when they are separated by the air; therefore, the amount of electricity moving in the oscillating discharge is much greater.

In addition, the oscillator with insulating liquid has another incomparable advantage well known to Righi and later implemented by Marconi.

It is in fact known to those who have repeated Hertz's experiments, that in order to have good results it is essential to keep the metal surfaces between which the spark is produced perfectly clean, which is why they must be cleaned at very short intervals, for example with sandpaper. With vaseline oil oscillators no special care is necessary, since they continue indefinitely to produce perfectly constant effects, even if after a long use the liquid has become very black due to carbonization, and a black deposit has formed on the two balls [68, p. 489]. [emphasis added]

Another issue that Marconi touches in his patent concerns the directionality of the signal. According to Marconi, when you want the signal to be sent in one direction only, the oscillator ( $d$ and $e$ in side and front view in Fig. 10) should be placed "in the focus or focal line of a reflector directed to the receiving station." The cylindrical parabolic reflector ( $f$ in side/front view in Fig. 10) was made "by bending a metallic sheet preferably of brass or copper." As it might be seen by comparing Marconi's setup with an 1894 schematic of Righi's apparatus, where the oscillator ( $E$, F, Fig. 11) was at the focus of a copper "cylindrical parabolic reflector" ( $A B C D$, Fig. 11) [68, pp. 491-492], and with a later photograph captured in Righi's laboratory [59] (Fig. 12), the similarities are, once again, striking.

The novelty introduced by Marconi in the patent, on the other hand, concerns the possibility of overcoming great distances. In that case, instead of the arrangement with the reflector, Marconi considers it preferable to resort to one or two large metallic plates, suspended with isolating wires to a tall vertical pole, connected to one end of the oscillator spheres, while the other end is connected to ground (Fig. 13). Marconi discovered that "the larger the plates at the transmitter and receiver and the higher they are from earth and to a certain extent the further apart they are the greater is the distance at which correspondence is possible" [49, p. 10, lines 50-53].

Summing up, Marconi's transmitter was "Righi's form of Hertz radiator," as admitted by Preece himself in his lecture. As we have seen, the analysis of UK patent 12039/96 shows that Marconi's improved transmitter was, down to the smallest details about arrangement of spheres, characteristics of the vaseline oil separating the inner spheres, and cylindrical parabolic reflector, a form of Righi's oscillator. Significantly, however, while the "Hertz radiator" is explicitly mentioned in the context of the simplified form of apparatus in Marconi's patent (see A in Fig. 7) [49, p. 3, line 27], Righi's name does not appear in the description of the improved version of the patented apparatus. Likewise, Righi's name does not appear even in the claims made by Marconi at the end of his patent. Claim n. 14 concerns indeed "transmitters substantially as described and shown in Figs. 6 and 7" [49, p. 12, line 34], where the figures show two variants of Righi's oscillator with the only replacement of the two inner spheres with two semispheres separated with oil. 


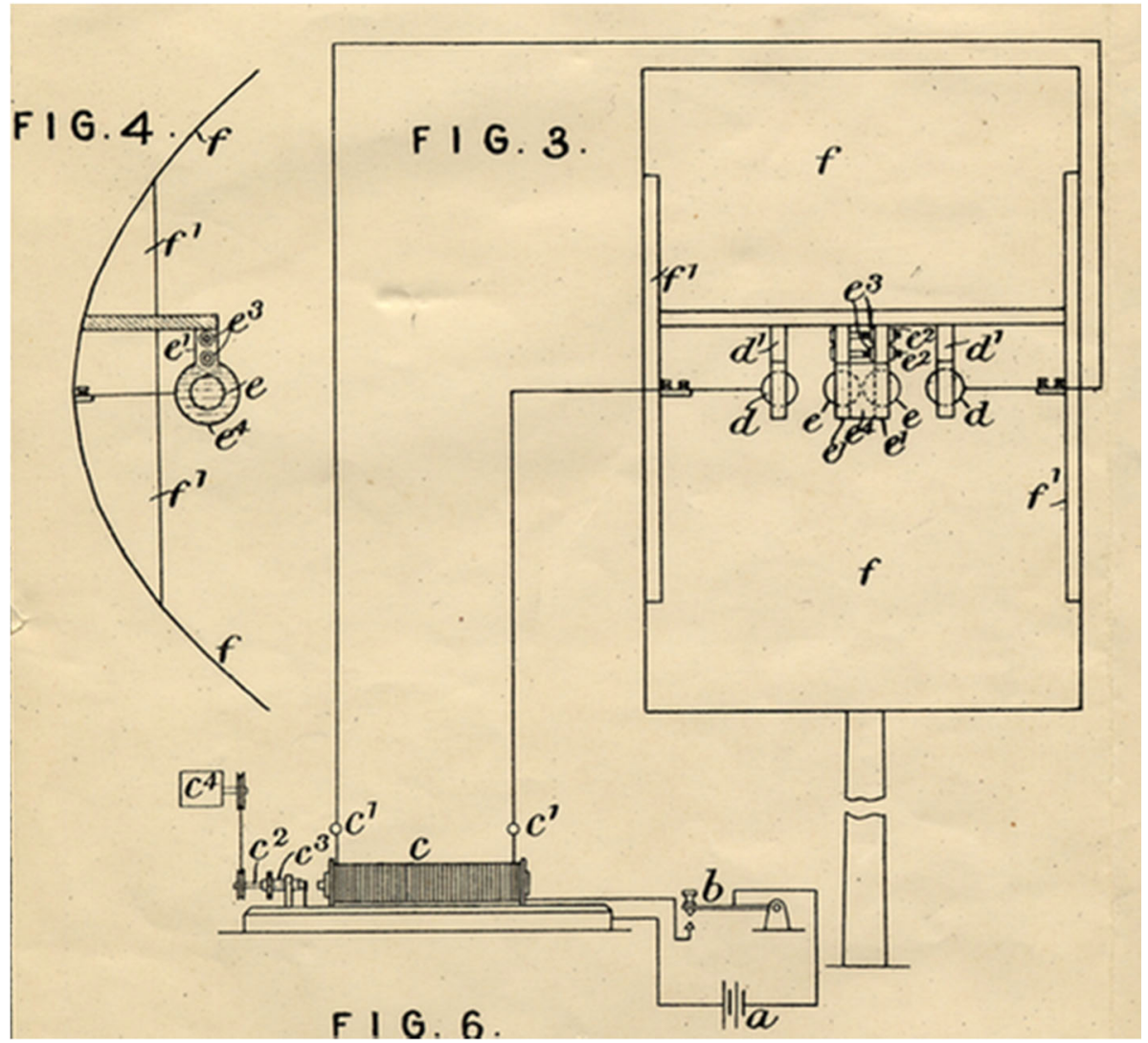

Fig. 10 Schematics of Marconi's reflector $(f)$, with the four spheres oscillator $(d$ and $e)$ at its focus in side and front view [49, Figure 3-4]

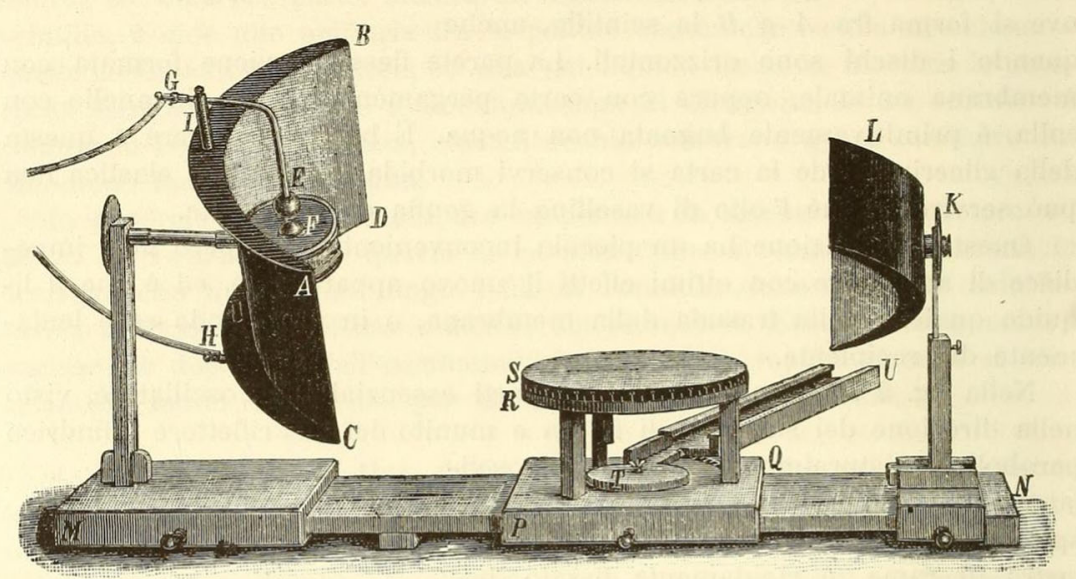

Fig. 11 Diagram of Righi's oscillator $(E, F)$ at the focus of a cylindrical parabolic reflector $(A B C D)$. On the right side can be seen the analogous parabolic reflector at whose focus Righi placed a receiver made of a layer of silver with a thin incision across its center, which acted as a dipole antenna [68, p. 492]

\section{The Italian academy honors Marconi}

In the last years of the century, Marconi kept giving more and more impressive demonstrations about the power of his telegraphic method. In July 1897, he gave a demonstration to the Italian Government in the Ligurian city of La Spezia, where wireless signals were sent over a distance of twelve miles, and in March 1899 he established wireless communication between France and England across the English Channel. The communication across the Channel took place over a distance of $50 \mathrm{~km}$. In Wimereux, near Boulogne, the installation consisted of a pole about 


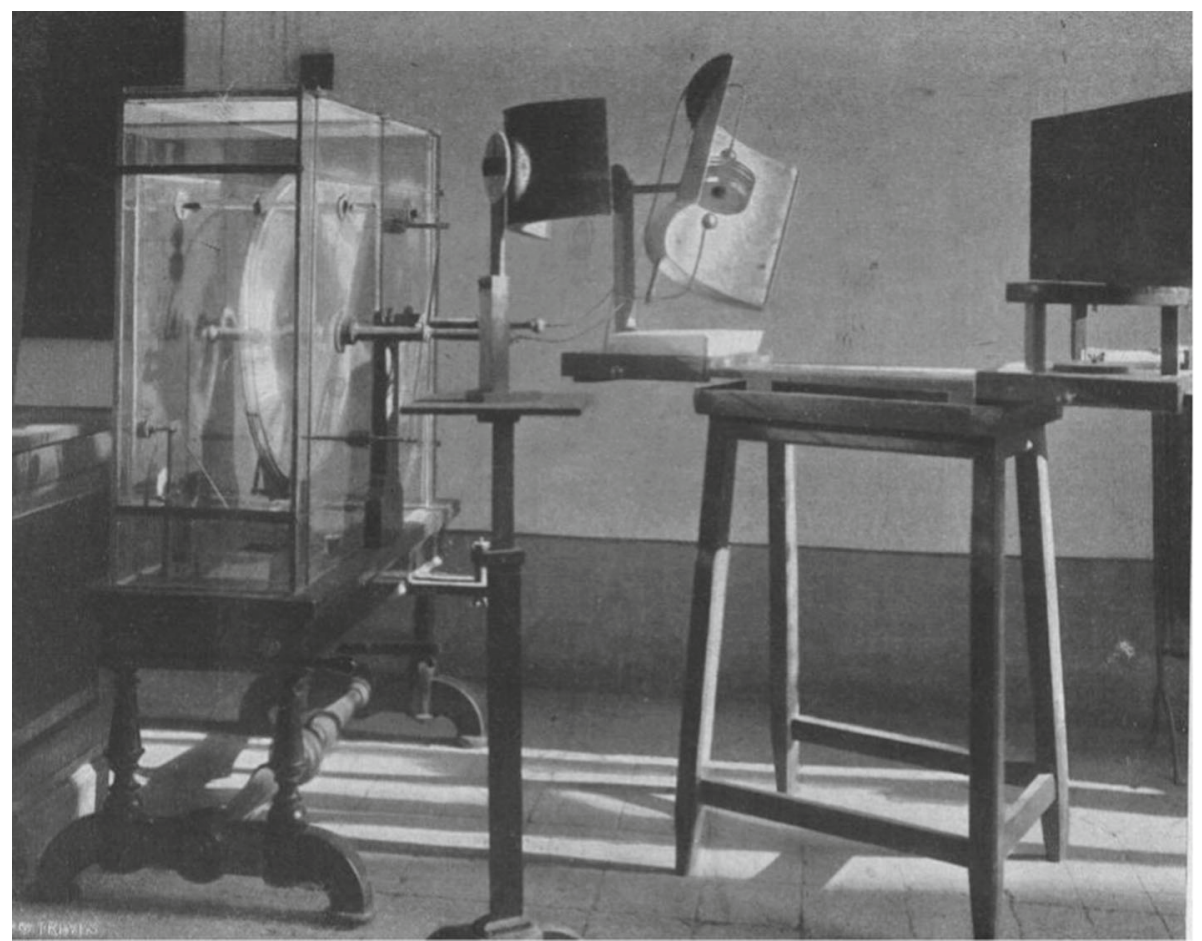

Fig. 12 Photograph captured inside Righi's laboratory at the University of Bologna. It shows the oscillator at the focus of the reflector (in the middle, upper part of the photograph) [59, p. 170]

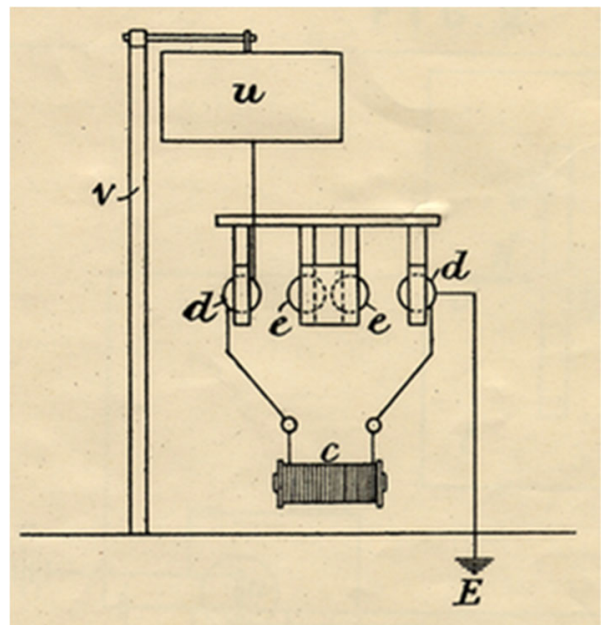

Fig. 13 Diagram of Marconi's improvement of the transmitting instrument, where one end of Righi's oscillator ( $d$ and $e$ ) was connected to a metallic plate $(u)$ suspended through an insulating wire to a tall vertical pole $(v)$ and the other end was connected to ground $(E)[49$, Figure 10]

thirty meters high, while in Foreland the British Government had made available a small room on a lighthouse. As outlined, for example, by one of the main Italian weekly magazines, La Domenica del Corriere, "the entire telegraph apparatus was placed on a small table. The dispatches were transmitted with mathematical precision and a speed of fifteen words per minute. Not an error, not an alteration" [31]. The news was accompanied by a splendid illustration showing Marconi behind his telegraphic apparatus in a pose similar to that of the Strand magazine photograph (Fig. 14). Another impressive achievement occurred in January 1901, when "on the first attempt" wireless communication was effected in southern England between a station at the Lizard, in Cornwall, and St. Catherine, Isle of Wight, "over a distance of 186 miles-Marconi reported - which I believe is the record distance over which signals have been sent through space without wires" [50].

Righi's attitude, though always marked by courtesy and admiration for Marconi's achievements - as opposed to the harshly critical feelings of his British friends Lodge and Thompson - kept being ambivalent in the years to 


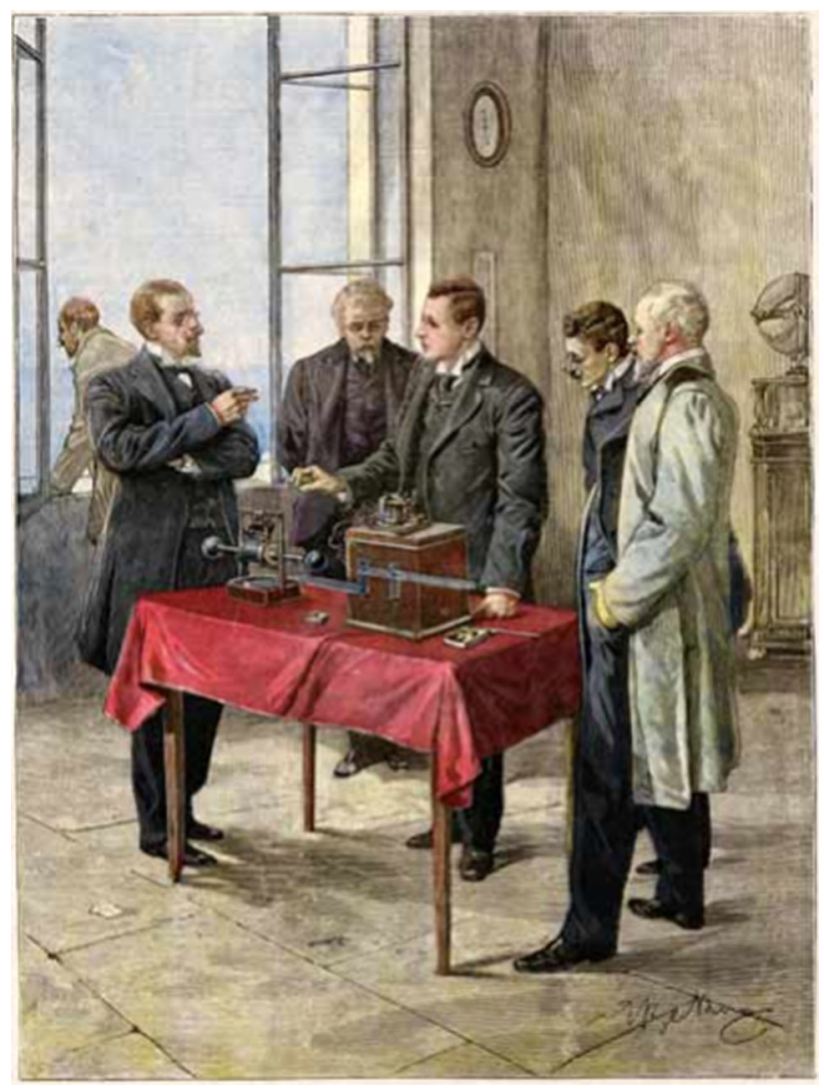

Fig. 14 Marconi during the English Channel experiment. This illustration, published on the Italian weekly magazine $L a$ Domenica del Corriere on April 23, 1899, mimics the famous Strand magazine photograph, with Righi's oscillator on the left and Marconi's closed box on the right [31]

come. Though laudatory toward Marconi for his successes, Righi often revealed a certain bitterness for the lack of recognition of his merits. Emblematic in this regard is a letter written by Charles Guillaume to Righi on March 15, 1900. Guillaume, who eventually will receive the Nobel Prize in Physics 1920, answered what must have been a rather bitter letter from Righi:

Part of your letter saddened me greatly. My colleagues and I thought, in fact, that M. Marconi had taken great advantage of your admirable experiences to make a fortune. But we didn't think he would have been so reckless. Your letter leaves no longer any doubt in our mind; he stole the fruits of your labor from you. [...] There is an injustice to be repaired here [33].

A case in point of Righi's attitude toward Marconi is the awarding of the prestigious Matteucci Medal ${ }^{6}$ of the Italian National Academy of Science "detta dei XL" (henceforth, Academy of the Forty), a medal to be yearly awarded "to an Italian or foreign physicist who, with works or discoveries, has contributed most to the progress of science" [65].

The commission for awarding the medal, for the year 1901, was formed by the academicians Pietro Blaserna (1836-1918), who held the chair of Physics at the University of Rome and who was Senator of the Kingdom of Italy, Antonio Ròiti (1843-1921), Professor of Physics at Istituto di studi superiori in Florence, and Righi, at that time holder of the chair of Physics at the University of Bologna.

In his letter to Righi, dated May 6, 1901, Blaserna set in unequivocal terms his and Ròiti's "way of seeing": the Matteucci medal should be awarded to Marconi and - the less than enthusiastic - Righi had to be the rapporteur!

We believe that the time has come to acknowledge Marconi and we would like to award him the Matteucci medal. [...] I know that you have complained about him, and with reason. [...] His patent was very weak and without your works it would not have been possible. [...] But it must be recognized that from that day on he

6 The medal was named after Carlo Matteucci (1811-1868), one of the main Italian physicist of nineteenth century and pioneer in the bioelectricity studies. Also, he was Risorgimento patriot, Senator of the Kingdom (1860-1868) and Minister of Education (1862). 
has walked a lot and a lot. [...] He managed to telegraph at 200 English miles and use a consonance principle that allows him to communicate with a specific station excluding all the others. I have seen abroad, that his work is very much appreciated and would pain me a lot, if foreign countries preceded us in recognizing his work. Ròiti also thinks so and that is why we turn to the nobility of your soul, because not only do we want to get along with you, but we also believe that you will take on the task of drafting the report. I'm sure everyone will highly appreciate your conduct. I therefore ask you, also on behalf of Ròiti, to not only join us, but to write the report, on which we give you ample power [4].

In his undated reply, Righi expressed his disagreement with Blaserna and Ròiti way of seeing.

Thank you very much for your affectionate letter, from which it seems to me that [...] perhaps it would be easy for an agreement to arise between us regarding the award of the well-known medal. However, I would like to wait to collect the information, which I have already tried to obtain by contacting various English physicists: they are the ones who see the thing we are interested in knowing more closely. I would have done this research anyway, because [...] I have to write a book on wireless telegraphy within the year. I have already had some answers and to tell the truth they are not very favorable to Marconi; but I am waiting for other data and above all copies of patents of various inventors. But there is no point in discussing this between you and me, while Ròiti is of the opinion that he will certainly award the medal based on the first invention (if the word can be used). [...] I told him that in order not to be an obstacle I am willing (indeed I wish) to ask the President to replace me in the Commission for the awarding of the medal [75]

Blaserna replied to Righi's letter on May 22 by reiterating his agreement with Ròiti's view "that the relationship, favorable, be made without the delay that you desired." Marconi "has left all his emulators behind him splendidly," as demonstrated by the recent wireless communication between the Cape Lizard and the Isle of Wight. For this reason, Blaserna expressed his firm belief that "any delay would be wrong on our part."

So, be good and get to work. You know the matter so well that the report would be done in two hours. Remember that it doesn't need to be long. Two printed pages are more than enough. And if I insist that you do it, it is not only because you are the youngest of us, but also because I feel that this relationship will do you honor [5]. [emphasis added]

On June 18, Ròiti wrote to Righi to express his confidence that Righi "will not take it long enough to frustrate the decision" taken by him and Blaserna. According to Ròiti, "we shouldn't judge as the Patent Office would do; and besides, you will be completely free to surround your motives with all imaginable cautions" [79]. And, again on June 25, Ròiti wrote to Righi to express his "desire that you find a way to draft the report in such terms as to be able to present it to the public as your thing. If you cannot find the reasons that allow you to write the word rapporteur next to your signature, the only way out will be that the three signatures appear indiscriminately without special attributes; because you will understand well that I do not want to be the crow that dresses in the peacock's feathers, and I cannot accept the suggestion that I sign myself as rapporteur" [80].

Righi eventually agreed to be the Academy of the Forty's rapporteur for the Matteucci Medal and the relation, drafted on June 30, was a model of conciseness (Fig. 15):

As soon as our Commission began its work, a question arose that needed to be resolved before proceeding to concrete proposals. One of us [i.e. Righi] opted that the person worthy of the Matteucci medal should only be sought among physicists who in recent times contributed more effectively to the rapid progress of science; the other two Commissioners, on the other hand, were of the opinion that that coveted distinction could possibly also be accorded to those who, while making use of known means and principles, had obtained eminent results in the field of useful applications. While each of us remained steadfast in our own conviction, the examination of the previous awards of the medal helped to settle the question. In fact, it seemed to us that in the past the broadest criterion of choice was adopted, that is, as it was accepted by the majority, and it was agreed to keep this criterion.

When arose within our Commission the proposal to award the medal to Mr. Guglielmo Marconi, this proposal was accepted and endorsed by the Commission itself. Indeed, the extremely promising success, which has so far crowned the tests carried out also on a large scale by the young inventor, is so well known that we consider it superfluous to mention it here more than a fleeting mention [81].

As we have seen from our analysis of the correspondence, the disagreement between Righi and the other two commissioners was not about the eligibility of recipients contributing to applied researches via "known means and principles," as reported in the June 30 relation, but, rather, about the recipient itself (i.e. Marconi), whose patents, according to Righi, were still a controversial matter. Eventually, Righi, the youngest among the commissioners, accepted obtorto collo the decision of Blaserna and Ròiti, provided that the relation is drafted in a concise way. So concise, that Blaserna later complained to Righi that he would have "desired it a little more detailed" [6]. 


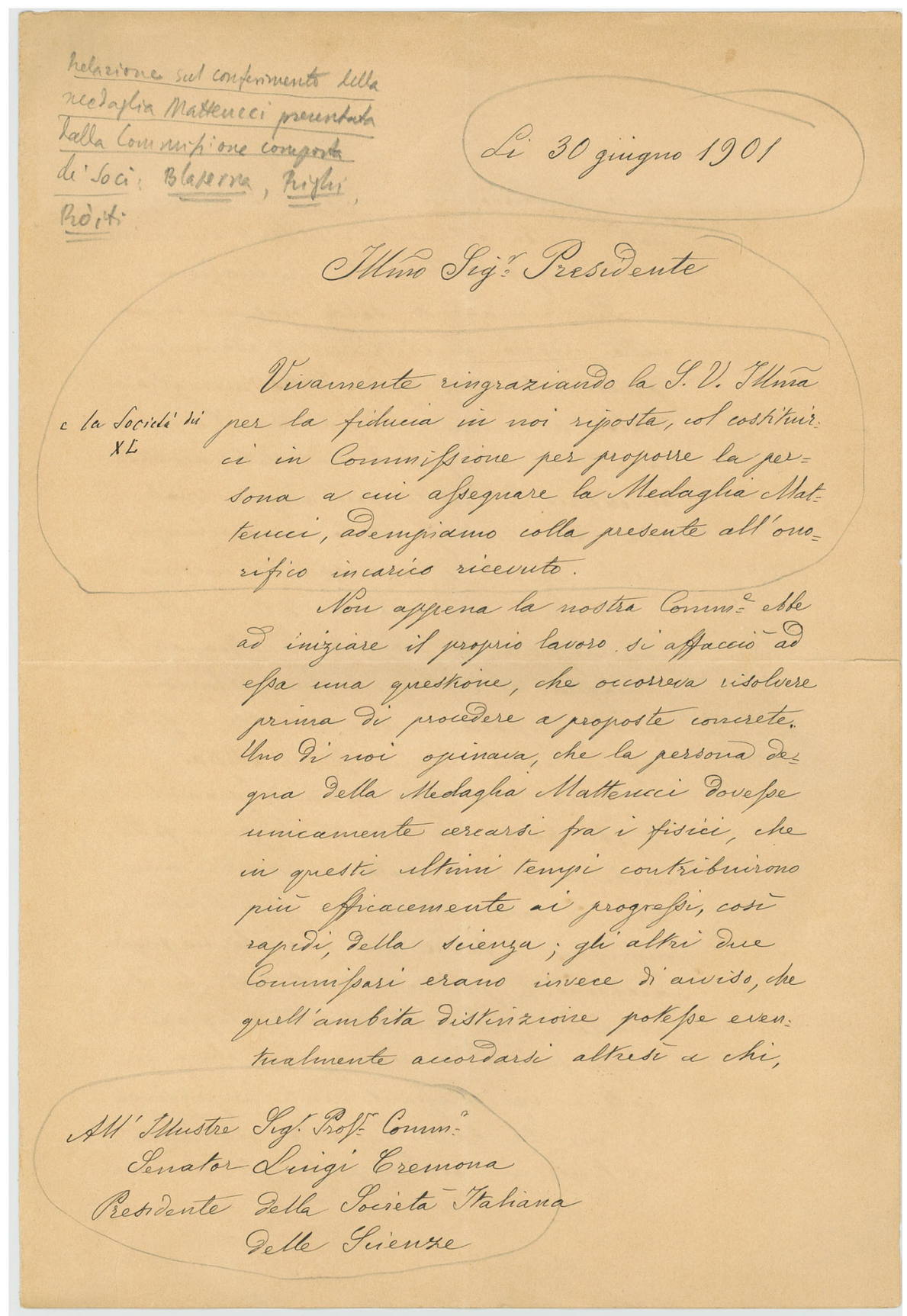

Fig. 15 Handwritten draft of the first page of the relation for the awarding of the 1901 edition of the Matteucci Medal [81]

Again, almost exactly a year later, on June 1, 1902, the whole $2^{\circ}$ category of the "Class of Physical, Mathematical and Natural Sciences" of the Accademia dei Lincei in Rome, of which Righi himself was part, unanimously decided to confer to Marconi, "in an extraordinary way and out of competition," the "Santoro prize" of 10,000 Lire. This prestigious prize, which was assigned every two years for works in the domain of applied sciences, was granted to Marconi "for his ingenious inventions in wireless telegraphy."

The motivation for the Santoro prize was likely written by the rapporteur of the proposal, Blaserna, at that time Vicepresident of the Accademia dei Lincei. Blaserna's proposal, though obviously enthusiastic toward Marconi, paid special attention to those who entered this field first, and notably to Righi. 
Marconi is generally recognized as the first who had the fruitful idea of using Hertzian waves, not to send a signal a few meters away - as Righi, Lodge and various other scientists had already done, to whom the credit belongs to have entered this way first - but to make it the basis of a telegraphic system proper [61].

Later, in 1903, Righi reminded a reporter that the Academy of the Forty had awarded Marconi the Matteucci medal in 1901 and that the Accademia dei Lincei had awarded him in 1902 the Santoro prize and diplomatically concluded: "I am pleased to have contributed to it in both cases" [20].

\section{The Saturday Review controversy}

In his relation for the Santoro prize, Blaserna pointed out that to the already existing devices Marconi added, for this purpose, the use of the vertical rod and "significantly improved the coherer, already used before."

Coincidentally, the question of the coherer, and the related 12039/96 patent, was, in those weeks, once again topical. On June 14, 1902, Thompson wrote to Righi on the issue of the "invention" of Marconi. In this letter, Thompson acknowledges to Righi the improvements he had made not only to the oscillator, but also to the "detector" (i.e. the previously discussed improvement of Hertz's "resonator"):

[Marconi] is sadly lacking on the courtesy of acknowledging his indebtedness to those from whom he has learned. I, for one, have never forgiven him for the mode in which he treated you. He learned from you of your researches on Hertz waves, and of your improvements of the oscillator and of the detector, and forthwith he comes over to England and patents them in his own name as his own inventions, and at the same time he patents as his own the automatic tapping of the coherer, which is due to Lodge [95].

On July 5, Thompson wrote again to Righi to inform him he "had a lot of correspondence as the result of my letters in the Saturday Review, in which I exposed the mean conduct of Sig. Marconi" [96]. In the period between April and July 1902, Thompson was indeed protagonist of a heated controversy concerning the wireless telegraphy on the pages of The Saturday Review (and, also, on the pages of The Times). One of the focus of this controversy was just Marconi's receiver.

The incipit of his April 5, 1902 article for The Saturday Review, made it clear from the beginning Thompson's viewpoint: "Although Signor Marconi is not the inventor, but the skilled exploiter, of telegraphy without wires, everyone must admire the splendid success of his achievement in sending intelligible signals over fifteen hundred miles across Atlantic [emphasis added]" [93, p. 424-425]. When, on December 12, 1901, Marconi succeeded in making the letter "S"-represented by three ticks - to hiss across the Atlantic, from the station at Poldhu, Cornwall (England), to St. John's, Newfoundland (Canada), it was immediately understood, to the alarm of the Anglo-American Cable company (whose method of communication, via submarine cable, appeared to be in direct competition with wireless telegraphy), that he had solved the problem of telegraphing across the Atlantic without wires (e.g. see [58]). However, according to Thompson, this did not diminish Marconi's unfairness toward Lodge.

One of the main arguments produced by Thompson to support his idea that Marconi was just the "exploiter" of wireless telegraphy, was the nature of the receiver used by the Italian scientist. As we have seen above, in the abstract of the lecture delivered by Preece and in the text of the 12039/96 patent, Marconi's receiver was a coherer consisting of a small glass tube into which two silver pole pieces tightly fitted, the half-millimeter space between them being filled with a mixture of fine nickel and silver filings mixed with a trace of mercury. The tube, which was exhausted to a vacuum of $4 \mathrm{~mm}$, formed part of a circuit containing a local cell and a sensitive telegraph relay. In its normal condition, this metallic powder was virtually an insulator, but when Hertz waves fell on the particles they were marshalled and arranged in such a way that they became a conductor. Hence, a current passed which could be used to ring a bell or indicate a signal in other ways. But in order to apply this device to practical work it was necessary to have some means of again rendering the filings non-conductive, and this Marconi managed by making the local current vibrate a small hammer-head against the glass tube, thus shaking the filings back into an insulating condition [83].

As recollected by Thompson, however, and as emphasized in his letter to Righi, Marconi's receiver was just a slightly modified version of Lodge's coherer:

[Lodge's] "coherer" [was] a sensitive tube containing minute metal filings, by means of which a local battery is relayed on to a suitable telegraphic instrument, usually a Morse sounder or recorder. The coherer is kept in its sensitive state by receiving gentle vibrations from an automatic "tapper". Every time that a spark is caused to pass in the oscillator a flight of ethereal waves is sent out; and each such flight of waves acting through the coherer at the receiving end delivers a signal in the telegraphic instrument [93, p. 424].

Afterwards, according to Thompson, Marconi had merely: "increased the range of working from the two hundred yards of Lodge's earlier successes up to ninety miles and more; he elongated the extended arms or aerial conductor; he used finer powders in the coherer; he used more sensitive telegraphic receivers." 
When Signor Marconi came to this country five years ago [...] he was still employing the Righi "oscillator", and the method of Lodge, with a coherer to relay the signals to a telegraph instrument, and an automatic tapper. From the patent which he took about that time - a document in which he apparently puts himself forward as the inventor of oscillator, coherer, tapper and all - it would appear that the only real point of novelty that he could embody in his claim was that of connecting one end of his coherer to the earth while the other was connected to an elevated and insulated conductor. All else is simply detail or surplusage [93, p. $425]$.

Thompson's argument was the same as that previously put forward by Lodge in his June 22, 1897 letter to The Times, where he had written that restoration to sensitiveness of his coherer "was effected by an electrically-worked hammer" [47]. As to the better way to operate an automatic tapping of the coherer, Lodge wrote in 1894 that "an electric bell [...] close to the tube is, perhaps, not the best vibrator; clockwork might do better, because the bell contains in itself a jerky current, which produces one effect, and a mechanical vibration, which produces an opposite effect" [45].

Marconi's response to Thompson's claims was not long in coming. On May 3, he replied to Thompson point by point. Marconi observed that the elements of his invention which Thompson disposed of as "detail and surplusage" happen to be precisely those "which make the whole difference between workableness and unworkableness in a wireless telegraphic apparatus of the type in question." He emphasized that when in 1896 and 1897 he showed to the authorities of the British Post Office the working of his telegraphic apparatus, "no description of any other practically workable installation of wireless telegraphy based on what are known as Hertzian waves or highfrequency oscillations had been made public." But the core of Marconi's reply, concerned a detail of Lodge's coherer:

Professor Lodge had never described an automatic tapper, which Professor Thompson states to be an essential feature of his "method", by an "automatic tapper" meaning one such as been used by me, worked directly or indirectly, that is through the interposition of a relay, by the same current as that which passes through the coherer. A tapper such as described by Professor Lodge, worked continuously by a separate current, has been demonstrated to be of no good service [emphasis added] [51].

Marconi had a point, which Lodge had made before, perhaps to Thompson's unawareness. In his May 10 rejoinder, Thompson correctly observed that the coherer was crucial to Marconi's patent. Such a patent had indeed no fewer than nineteen claims, "nearly all of which relate to coherers - those sensitive tubes of imperfectly conducting iron filings which require to automatically tapped to keep them sensitive." However, he missed the point when, to counter Marconi's claim above about the unsatisfactory character of Lodge's tapping system, he replied that "if this kind of automatic tapping is not of utility, why did [Marconi] draft his claims so as to include it? Does he not know that if he admits inutility of something within his own [patent] claims, his admission renders his patent invalid?" [94]. As it was later observed by the historians of wireless telegraphy, if the patentability of the whole set of Marconi's claims was extremely uncertain, however, "without doubt, Marconi could safely patent two things" [36, p. 740], one of whom was the tapper activated by the relay current (the other thing safely patentable was, as Blaserna had reported in his relation for the Santoro prize, the vertical rod, or antenna). Even Lodge, in his June 1900 Report to the Chief Engineer of the Government Telegraphs, had admitted Marconi's novelty in the tapping system: "what Marconi can righteously claim is that he had made the coherer work dependably and give good signals in ordinary Morse code" [37, p. 206].

Though Marconi's tapping system was a clear improvement upon Lodge's apparatus, it was Righi who most notably emphasized a few months later that the receiver devised in 1895 by the Russian physicist Alexander Stepanovich Popov (1859-1906) somewhat anticipated the way in which Marconi connected his coherer. In his 1903 book on wireless telegraphy, Righi wrote indeed that "the new features of Popov's apparatus are the use of an electrically moved hammer or electric bell, to automatically restore the initial resistance of the coherer, and the use of a vertical conductor, called later antenna, for receiving the waves" $\left[76\right.$, p. 286]. ${ }^{7}$ Though, the later claims about an alleged priority of Popov upon Marconi as the actual inventor of the radio holds no water [2,87], the diagram of Popov's coherer reproduced by Righi in his book shows that Popov's apparatus anticipates Marconi's solution for decohering the coherer (Fig. 16). As explained by Righi:

The arrangement adopted [by Popov] includes first of all a tube with filings (coherer) AB, inserted in the circuit of a battery $\mathrm{P}$ together with the electromagnet $\mathrm{C}$ of a relay. When the filing, by the action of electric waves, becomes conductive, the anchor $\mathrm{D}$ is attracted to the electromagnet $\mathrm{C}$, with which contact $\mathrm{E}$ is established, which closes the branch circuit FGE including the electromagnet $\mathrm{G}$ of an electric bell. The anchor $\mathrm{H}$ is then attracted, and the hammer it carries strikes the bell; but it immediately falls back, and striking the filing

7 The English translation of this excerpt was also reproduced in Vendik [101] with the curious omission of the crucial adverb "automatically." 


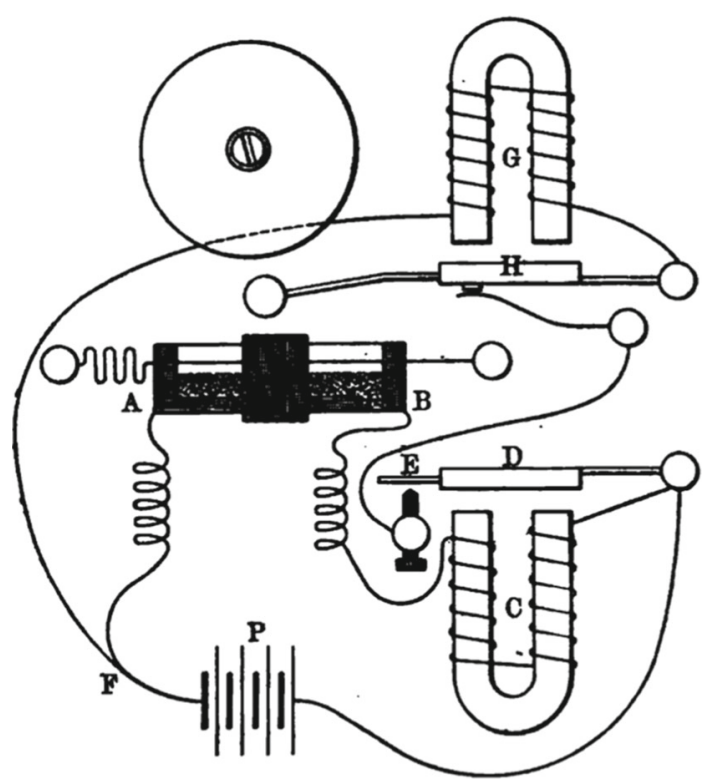

Fig. 16 Diagram of Popov's arrangement of the coherer in Righi's book about wireless telegraphy (76, p. 284)

tube, it shakes it enough to recover its initial resistance. [...] In this way, the device is automatically returned to the primitive condition $[76$, p. 285$] .^{8}$

Thus, although Righi should be remembered above all for his experiments on the properties of electromagnetic waves in the laboratory and corridors of the University of Bologna, and for the development of his oscillator, which much contributed to the development of wireless telegraphy and which was eventually adopted by Marconi in his patent, Righi was also much interested in the improvements of the coherer techniques. For example, in his May 1897 interview, Righi reported having read that in a recent conference a Rome Engineer had used a coherer in a way reminiscent of Popov's arrangement (i.e. with an electric bell "whose hammer, as well as banging on the bell, also hits the tube, and thus returns, after each signal, the primitive sensitivity") [30]. Also, in November 1897, Righi discovered that a suitably designed tube filled with rarefied air, where specially folded platinum wires are connected to a battery of suitable voltage, one might detect hertzian waves from an oscillator "with a sensitivity that seems to me little different from that obtained by using a coherer" [72]. In his book on wireless telegraphy, Righi devoted also a paragraph to that detector, however he was forced to admit that "the most sensitive among the electric wave indicators seems to be the one called coherer by prof. Lodge" [76, p. 184].

Righi's oscillator and Lodge's coherer were an integral part of the "Marconi system." However, as Dessau explained a few months later in the book La telegrafia senza filo (authored by Righi and Dessau), this was not the mere juxtaposition of two pre-existing equipments:

In the essential details of his apparatus, Marconi therefore had precedents, so that his invention, also according to his own words in the description of the patent, largely refers to the way in which the devices are constructed and connected to each other. Nor [...] could he be given priority in the idea of remotely transmitting dispatches by means of those devices. But he has the indisputable merit of having taken a bold initiative, where others had only made timid proposals, and of having carried into the practical field what others had only glimpsed or achieved on a smaller scale. But his ingenuity and inventive faculties were fully revealed later, by the skill with which he overcame the numerous difficulties, and by the many modifications and additions of detail largely essential for practical success, which were introduced by him and brought together in that whole, which can rightly be called the Marconi system [76, pp. 287-288].

\section{Chasing the Nobel Prize}

In 1909, at the age of 35 years, twelve years after having been granted the patent for "improvements in transmitting electrical impulses and signals," 8 years after sending an "S" from one corner of the Atlantic to the other via wireless telegraphy, and six months after the first SOS distress call ever sent after a shipwreck, Marconi was awarded

8 Righi's diagram is derived from the English translation of Popov's paper [60]. 
the Nobel Prize in Physics. As above outlined, the prize was jointly awarded to Marconi and Karl Ferdinand Braun [3] "in recognition of their contributions to the development of wireless telegraphy" (as reported in the presentation speech given by the President of the Royal Swedish Academy of Sciences, Braun was awarded for his improvements to the wireless telegraphy and, notably, because he "made a modification in the layout of the circuit for the dispatch of electric waves so that it was possible to produce intense waves with very little damping") [35]. However, while Braun was a respected electrical engineer, director of the Physical Institute and professor of physics at the University of Strasburg, Marconi was, in all respect, an outsider to the physics community, lacking a formal academic education.

1909 was an interesting year in the history of Nobel Prize in Physics. It was in that year that the Wright brothers, Wilbur and Orville, did receive 16 nominations cumulatively for the demonstration of the first human flight in a power-operated airplane. Henry Farman and Gabriel Voisin, French rivals in aviation of the Wright brothers, also received 16 nominations cumulatively for 1909 prize [86]. Max Planck, who eventually got the prize in 1918 "in recognition of the services he rendered to the advancement of energy quanta," received 9 nominations in 1909. George Ellery Hale, American astronomer known for his development of important telescopes and for his research in solar physics made through them, got 7 nominations; and 6 were the nominations obtained that year by Heike Kamerling Onnes, the Dutch physicist who got the Nobel Prize in Physics four years later "for his investigations on the properties of matter at low temperatures which led, inter alia, to the production of liquid helium" [66].

At the year of his award, Marconi had comparatively very few nominators: Gustaf Granqvist, member of the Nobel Committee for Physics, and Hjialmar Tallqvist, professor of physics at the University of Helsinki (and, as such, a qualified nominator by statute). Braun had just one nominator, Granqvist. Anyhow, independently of the number of nominations, the Nobel Prize was awarded at the discretion of the Royal Swedish Academy of Sciences. The procedure stipulated indeed that the Physics Committee prepares a general report on the relative merits of the nominees, indicating those most likely to be awarded the prize. A special report on the work of the prospective prizewinner(s) is annexed and a final recommendation is sent to the Physics Section for a vote and, finally, to the Royal Swedish Academy of Sciences for a final vote [66, pp. 419-420]. In this respect, it is important to emphasize that though the choice of rewarding a practical application was unprecedented, Marconi's invention nicely met the criteria for the award of a Nobel Prize, that is that the work rewarded "should constitute 'discoveries', 'inventions' or "improvements" ", that this work should represent "the most modern results," and that this work should "have conferred the greatest benefit on mankind" [19, p. 151].

In the former years, Marconi was for four years nominee, mainly by Italian scientists, such as the physicists Blaserna and Ròiti (who had previously awarded to him the Matteucci medal), the chemist Stanislao Cannizzaro (who was member of the $2^{\circ}$ category of the "Class of Physical, Mathematical and Natural Sciences" of the Accademia dei Lincei who conferred to him the Santoro prize), and the astronomer Giovanni Schiaparelli. Significantly, when Marconi had the opportunity to be nominator, in the year immediately following the achievement of the Nobel (1910), he nominated a foreign physicist (Poincaré) and not an Italian physicist (Fig. 17).

In particular, Marconi did not nominate Righi, notwithstanding Righi had been "chasing" the Nobel prize for a number of years and will continue until the year of his death (1920). Righi was indeed nominated continuously for sixteen consecutive years, from 1905 to 1920 (Fig. 17) without succeeding to get the coveted prize!

Of course, Righi was a whole another story if compared to Marconi. He was an internationally renowned physicist, with many connections in the European physics community, and whose career was characterized by important works in numerous and different research fields of physics, not focused, as is the case of Marconi, on wireless telegraphy [42].

Since 1905, Righi engaged on an intense lobbying of fellow physicists. Such a lobbying was particularly intense soon after the award to Marconi, when a concerted effort to support the candidacy of Righi was indeed made by four Italian scientists consulted by the Swedish Academy: the distinguished mathematicians and physicists Gregorio Ricci-Curbastro and Tullio Levi-Civita, and the geophysicists Giuseppe Vicentini and Luigi De Marchi (Fig. 17). As it was reported by Vicentini to Righi on December 12, 1909, the four scientists were individually invited by the Nobel Committee to make a proposal for the physics prize to be awarded for 1910: "We gathered yesterday for an exchange of ideas and we decided we had to propose you for the high honor." Given their perfect agreement, it was also agreed to make a collective proposal and, "since the proposal must be made for a specific study or discovery - Vicentini wrote - it seems to me and to the other colleagues that we have to put forward as preferred titles the set of researches that make up the Optics of Electric Oscillations [...] as well as the complex of those observations on electrical phenomena and radiation that have their crowning glory in the discovery and study of magnetic rays" [102]. If "Optics of Electric Oscillations" refers to the important Righi's research on the electromagnetic theory of light, the last reference in Vicentini's letter allows us to remember that Righi, in 1908 studied the influence of a magnetic field on discharge phenomena in gas tubes. To do this, he carried out a large number of new and suggestive experiences that he tried to interpret with the hypothesis of "magnetic rays." This hypothesis, which immediately aroused much clamor, in the end, however, "failed to pass important experimental tests" [7, p. 28].

One month later, on January 13, 1910, Lodge answered to Righi's query about the reception in England of the news about the recent award to Marconi. As it was observed by Lodge, "I have certainly remarked no sign 


\begin{tabular}{|c|c|c|c|c|}
\hline \multirow[b]{2}{*}{ year } & \multicolumn{2}{|l|}{ RIGHI } & \multicolumn{2}{|l|}{ MARCONI } \\
\hline & nominée & nominator & nominée & nominator \\
\hline 1901 & & & Pietro Blaserna & \\
\hline 1902 & & & Pietro Blaserna; John Fleming & \\
\hline 1903 & & & $\begin{array}{c}\text { Claes Adelskold; Pietro Blaserna; Antonio } \\
\text { Ròiti; Giovanni Schiaparelli; Elisa } \\
\text { Sidenbladh; Hjalmar Sjogren }\end{array}$ & \\
\hline \multicolumn{5}{|l|}{1904} \\
\hline 1905 & Henri Poincarè & & & \\
\hline 1906 & Henri Becquerel & & & \\
\hline 1907 & Angelo Battelli; Hermann Ebert & & & \\
\hline 1908 & $\begin{array}{l}\text { Michele Cantone; Oliver Lodge; Silvanus } \\
\text { Thompson; Frederick Trouton }\end{array}$ & & Pietro Blaserna; Stanislao Cannizzaro & \\
\hline 1909 & Vito Volterra & & Hjalmar Tallqvist; Gustaf Granqvist & \\
\hline 1910 & $\begin{array}{c}\text { Luigi De Marchi; Tullio Levi Civita; Gregorio } \\
\text { Ricci-Curbastro; Silvanus Thompson; } \\
\text { Giuseppe Vicentini }\end{array}$ & & & $\begin{array}{c}\text { Henri } \\
\text { Poincaré }\end{array}$ \\
\hline 1911 & Silvanus Thompson & & & \\
\hline 1912 & $\begin{array}{c}\text { Giacomo Ciamician; Orso Mario Corbino; } \\
\text { Vito Volterra }\end{array}$ & & & \\
\hline 1913 & $\begin{array}{l}\text { Giacomo Ciamician; Boris Golitsyn; Silvanus } \\
\text { Thompson; Vito Volterra; Pieter Zeeman }\end{array}$ & & & \\
\hline 1914 & $\begin{array}{l}\text { Giacomo Ciamician; Gaston Darboux; Luigi } \\
\text { Donati; Boris Golitsyn }\end{array}$ & $\begin{array}{l}\text { William } \\
\text { Crookes }\end{array}$ & & \\
\hline 1915 & Giacomo Ciamician & & & \\
\hline 1916 & Giacomo Ciamician; Luigi Donati & & & \\
\hline 1917 & Giacomo Ciamician; Camillo Golgi & & & \\
\hline 1918 & Giacomo Ciamician & & & \\
\hline 1919 & $\begin{array}{c}\text { Giacomo Ciamician; Camillo Golgi; Albin } \\
\text { Haller }\end{array}$ & & & \\
\hline 1920 & $\begin{array}{c}\text { Pietro Burgatti; Giacomo Ciamician; Luigi } \\
\text { Donati; Camillo Golgi }\end{array}$ & & & \\
\hline
\end{tabular}

Fig. 17 A comparative table of Righi's and Marconi's nominees and nominators until the year of death of Righi (data derived from "The Nomination Database" of the Nobel Foundation (Nomination Archive. NobelPrize.org. Nobel Media AB 2020. 15 Dec 2020. https://www.nobelprize.org/nomination/archive/)

of enthusiasm about the award of the Nobel Prize to Marconi. He is regarded, I think, as having developed the matter with great energy from the commercial point of view. I do not think he is seriously regarded as a scientific man. But I must say that I have had no communication from anyone on the subject either one way or the other" [48].

The day after Lodge's letter to Righi, Thompson, who had nominated Righi in 1908 and will again nominate him in 1910 and 1913, wrote to Lodge a "confidential" letter on a possible lobbying activity among the British physicists. As outlined by Thompson, "the procedure in nominating names for the Nobel prizes in Physics, is so far as English physicists is concerned, a purely individual one." Thompson correctly assumed that "Sig. Marconi was certainly not nominated by any consensus of British physicists. I doubt whether any British physicist nominated him." On the other hand, "I nominated (for the last 2 years) Sig. Righi, and I know more than one English nominator who voted also the same way" [97].

Another scientist consulted by Righi was artist turned physicist Thomas Tommasina who, in his January 19, 1910 wrote to Righi quoting the opinion of Henri Poincaré, who had already nominated Righi in 1905 but who was quite skeptical about his chances for 1910 "because the gentlemen are forced to a certain rotation between 
the nations and it is not likely that they will want to give two years in a row the physics prize to an Italian. The circumstances will undoubtedly be more favorable next year" [98].

An important Italian sponsor of Righi in his catch for the Nobel Prize was Orso Mario Corbino, successor of Blaserna at the Institute of Physics of the University of Rome, under whose directorship in the 1920s and 1930s flourished the nuclear physics school of Enrico Fermi. In 1912, Corbino actively supported Righi's candidacy, also through letters to the Nobel Committee. For example, on December 23, 1911, Corbino wrote to Righi having consulted Granqvist, Chairman of the Nobel Committee for Physics of the Royal Swedish Academy of Sciences (who two years earlier had nominated Marconi), for official information on the rules to be respected when submitting an application. Corbino, who wished to standardize the proposal to the previous ones so that there was a certain concordance in the choice of the most suitable Righi's researches, confessed to Righi that "this year's result drops your arms; they did not even associate, as it seemed, to the name of Wien that of Planck! And I wonder what value the referendum of the competent ones has in the Committee, not believing that many of them had actually proposed the first" [14] [emphasis added]. Granqvist replied to Corbino that the proposal should be motivée (motivated) and that "it will be a great pleasure for me and for my colleagues to take note of your proposals for the Nobel Prize." "I just hope they read them" was the disillusioned Corbino's comment [15]. As the Nobel Committee "want the prize to be given to a single research, to stay within the terms of the Statute," according to Corbino "it does not seem a good way to recall the candidate's entire scientific work." Therefore, he suggested to Righi that it was better to focus on his "researches on electric discharge" and to summarize them in this title: "electric shadows, photoelectric effects, the action of X-rays, studies on sparks, electric discharges between conductors of small capacity and related electromagnetic effects (electric waves), and finally discharges in the field and therefore research on magnetic rays and magneto-ionization" [15]. Corbino's suggestion was eventually accepted by Righi [16] and the proposal was sent to the Nobel Committee. As later commented by Corbino, "never as this time have I been sure the conscience of fulfilling a duty" [17].

Another Righi's supporter was the Dutch physicist Pieter Zeemann, well known for the discovery of the effect named after him, which earned him the Nobel Prize in Physics 1902. As reported by Zeeman in a letter received by Corbino on February 3, 1912: "Mr. Righi's brilliant and fruitful scientific work and his tireless ardor have always evoked my admiration. It was therefore a real pleasure for me to write a proposal to nominate Mr. Augusto Righi for the Nobel Prize to be awarded in 1912. I have just sent my letter to Stockholm, and I hope my proposal will help a little in a favorable decision. If the prize would be awarded to M. Righi it would be a fair tribute to the beautiful development of Italian physics" [18]. In commenting on Zeemann's laudatory words, Corbino told to Righi: "I am so happy about it, since I see the day coming when, finally, the due justice will be rendered to you" [18].

Needless to say, that day will never come.

\section{Two physicists in the Senate of the Kingdom}

Different in many respects, not least the outcome of the hunt for the Nobel Prize, Marconi and Righi shared a very prestigious honor: both of them were indeed nominated, by the King Vittorio Emanuele III, senators of the Kingdom of Italy. At that time, differently of the Chamber of Deputies, which was (and still is) elective, the members of the Senate of the Kingdom were appointed for life by the King [41].

Marconi was nominated senator on December 30, 1914, when he was just forty years old, for the "category 20" of art. 33 of the Albertine Statute (the constitutional charter of the Kingdom of Sardinia and then of the Kingdom of Italy), as one of "those who with eminent services or merits have brought honor to the homeland." ${ }^{9}$ As it was explained by the engineer Giuseppe Colombo, senator and rapporteur of the Senate commission charged with the verification of the titles of new senators, Marconi was made senator for his invention of wireless telegraphy [11].

In this regard, wireless telegraphy was previously brought to the attention of the Senate by another physicist made senator, the aforementioned Blaserna, who, in 1903, was rapporteur of the Senate Commission on the bill titled "Installation of an ultra-powerful telegraph station according to the Marconi System." And four years later Blaserna himself was again rapporteur of a wireless telegraphy bill on the installation of telegraph stations in the Italian colonies of Africa. Interestingly on the occasion of the 1903 bill, Blaserna reconstructed the history of the studies of electromagnetic waves in the Senate hall.

At the time of this bill, Righi was not yet in the Senate and one wonders what might have been his reaction to Blaserna's reconstruction of the history of wireless telegraphy. Righi was nominated senator on March 4, 1905, for the category 18, that is as a "member of the Royal Academy of Sciences after seven years since the nomination." 10

9 To this category belonged some "physicists-senators" who had distinguished themselves in the Risorgimento period, as Carlo Matteucci and Ottaviano Fabrizio Mossotti.

10 Initially, only the members of the "Royal Academy of Sciences of Turin" fell into this category (as a consequence of the fact the Turin was capital of Kingdom of Sardinia and, later, of the Kingdom of Italy), but later other academies 
Many were the topics touched by Righi and Marconi in the Senate. To focus on years of "cohabitation" in the Senate with Marconi (1915-1920), Righi dealt with education and research, with particular reference to the re-evaluation of the role of assistants. But Righi's activities in the Senate were not limited to this. He was, for example, one of the greatest promoters of new water derivation plants for energy purposes and of air mail [41, pp. 127-134, 139-141, 256-260]. As for Marconi, he intervened in the Senate on various matters in the 1915-1920 years. For example, on the energy issue, in 1916 Marconi questioned the government about the exploitation of lignite, a hard coal which, although of low calorific value, is available in Italy in significant quantities. Furthermore, he delivered a number of much appreciated speeches in the Senate concerning the Great War [41, pp. 77-82, 270-272].

Both Righi and Marconi stood out as two of the most active and appreciated protagonists in the Senate. At the time of Righi's death, in 1920, no less than eight senators commemorated him in the Senate. Although Marconi was not one of them, among those who commemorated Righi there were also prominent figures of the Italian culture, like the philosopher, senator and Minister of public education Benedetto Croce. Marconi, on the contrary, received much fewer commemoration speeches (two), one of which however was delivered by the Prime Minister himself, Benito Mussolini [41, p. 324, 329].

In fact, Righi and Marconi hardly ever found themselves in the Senate to intervene on the same issues. The only exception appears to be the commemorations for Blaserna's death on February 27, 1918. On that occasion, Righi said that Blaserna accomplished, among other things, "a very noble work for physics which today would be felt more than ever the need, that of encouraging young physicists and facilitating their careers" [13, pp. 4102-4103]. A few minutes later, Marconi expressed his regret for the death of Senator Blaserna, who "never failed to offer his encouragement, his interest, I would say his protection, especially to young people who were dedicated to solving problems in applied science" [13, pp. 4103-4104].

It is difficult not to see the images of two very different scientific lives, but united by a common passion for the electromagnetic waves, reflected in these words of commemoration of their late colleague, Blaserna.

It is difficult not to find in his reference to the careers, in universities, of young assistants, the passion with which Righi tried to work for them in the Senate in the best interest of pure science. And it is difficult not to find in the reference to the scientist who never failed to offer his encouragement to young people committed to solving problems in applied science, the autobiography of Marconi himself.

\section{Conclusion}

The essential elements and ingredients of wireless telegraphy were available within early 1890s physics. As we have seen from our analysis of Marconi's patent, his first transmitter was, down to the smallest details concerning the oil or the reflector to be used, a version of Righi's oscillator, previously described in the scientific literature. And his receiver was a slightly modified version of Lodge's automatic tapping coherer. But, of course, details make the difference. Though both Righi and Lodge were aware that Hertzian waves can be produced and detected at a distance, nobody before Marconi seriously attempted to use Hertzian waves with the goal of sending signals at a distance. Furthermore, the small changes made by Marconi to the oscillator, and especially to the receiver, were not "simply details or surplusage," as Thompson put it, but, rather, ingenious improvements made to known apparatuses after that the previous solutions have been "demonstrated to be of no good service," as Marconi put it.

Through his exploits in the field of wireless telegraphy, which have marked an era, Marconi got a Nobel Prize for which the time was ripe and, eventually, also a seat in the Senate of the Kingdom for having "brought honor to the homeland"; a Senate in which Righi already sat, thanks to his academic position. Despite his numerous scientific accomplishments and accolades, which largely had no direct connection with the wireless telegraphy, and despite intense scientific lobbying, the Nobel Prize feat failed instead to Righi, to his bitterness. Though Righi did not contribute directly to the invention of wireless telegraphy, for whose invention much of the credit goes to Marconi, Righi's experimental work and instruments in the domain of electromagnetic waves were crucial for such an invention. The sense of this story was perfectly grasped by the aforementioned Benedetto Croce, who in his commemoration of Righi in the Senate said so to his fellow senators: "Augusto Righi was one of those who in our days have held up the name of Italy in the domain of the sciences, in which that name was always glorious. Righi's reputation, which had formed among severe scholars, had spread to even a wider circle [...] because it was known that his investigations on electrical undulations and its oscillator were starting point for the discovery of wireless telegraphy. But Righi was and wanted to be a pure scientist" [12, p. 886].

We do not know if Marconi got where he got because he stood upon the shoulders of giants or also because he stood on the back of a donkey to the other bank of the Reno river. What we do know is that Marconi saw

and institutes were equalized with the former on the occasion of the appointment of specific senators, for examples the Accademia dei Lincei in Rome or the Royal Society of Naples. 
before others that, as forecasted by Crookes years earlier, wireless telegraphy was no mere dream of a visionary philosopher.

Acknowledgements We would like to thank Francesco Guerra for useful discussions and suggestions.

Funding Open access funding provided by Universitá degli Studi di Torino within the CRUI-CARE Agreement.

Open Access This article is licensed under a Creative Commons Attribution 4.0 International License, which permits use, sharing, adaptation, distribution and reproduction in any medium or format, as long as you give appropriate credit to the original author(s) and the source, provide a link to the Creative Commons licence, and indicate if changes were made. The images or other third party material in this article are included in the article's Creative Commons licence, unless indicated otherwise in a credit line to the material. If material is not included in the article's Creative Commons licence and your intended use is not permitted by statutory regulation or exceeds the permitted use, you will need to obtain permission directly from the copyright holder. To view a copy of this licence, visit http://creativecommons.org/licenses/by/4.0/.

\section{References}

1. Augusto Righi ed il telegrafo Marconi. Il Resto del Carlino, March 12, 1903

2. Barrett, Ralph and Godley, Margaret L. 1995. Popov and Marconi. Nature 376: 458

3. Bischi, Matteo. 2017. Who was Karl Ferdinand Braun?. Lettera Matematica 5: 253-259

4. Blaserna, Pietro. Letter to Augusto Righi, May 6, 1901, Accademia Nazionale delle Scienze detta dei XL, Fondo Augusto Righi (henceforth AXL), f. 37, 1. 165

5. Blaserna, Pietro. Letter to Augusto Righi, May 22, 1901, AXL, f. 37, 1. 166

6. Blaserna, Pietro. Letter to Augusto Righi, July 8, 1901, AXL, f. 37, 1. 167

7. Carazza, Bruno and Kragh, Helge. 1990. Augusto Righi's magnetic rays: a failed research program in early 20th-century physics. Hist. Stud. Phys. Sci 21: 1-28

8. Cardani, Pietro. 1921. In memoria di Augusto Righi. Nuovo Cimento 21: 53-157

9. Carrara, Sandro. 2016. The path to Radio: from Maxwell to Marconi, in Franco Maloberti and Anthony C. Davies (eds), A short history of circuits and systems. River Publishers, Aalborg, Denmark, pp. 41-44

10. Colombo, Giuseppe. 1905. Relazione della Commissione per la verifica dei titoli dei nuovi Senatori sopra la nomina del Sig. Prof. Augusto Righi, March 12, 1905. Fascicolo personale di Augusto Righi (ASSR, Senato del Regno. Segreteria. Fascicoli dei senatori, Augusto Righi, n. 1376)

11. Colombo, Giuseppe. 1915. Relazione della Commissione per la verifica dei titoli dei nuovi Senatori sopra la nomina del Signor Guglielmo Marconi, March 1915. Atti Parlamentari. Senato del Regno. Legislatura XXIV. $1^{\circ}$ sessione $1913-1915$. Documenti. Disegni di legge e relazioni.

12. Commemorazione (dei senatori Raccuini, Righi, Torrigiani Piero). 1920. Atti Parlamentari. Senato del Regno. Legislatura XXV. $1^{\circ}$ sessione 1919-1920. Discussioni. Tornata del 24 giugno 1920, pp. 876-886; 886

13. Commemorazioni (dei senatori Blaserna, Facheris e Ridolfi). 1918. Atti Parlamentari. Senato del Regno. Legislatura XXIV. $1^{\circ}$ sessione 1913-1918. Discussioni. Tornata del 27 febbraio 1918, pp. 4102-4104; 4102-4103

14. Corbino, Orso Mario. Letter to Augusto Righi, December 23, 1911, AXL, f. 87, 1. 330

15. Corbino, Orso Mario. Letter to Augusto Righi, January 7, 1912, AXL, f. 87, 1. 331

16. Corbino, Orso Mario. Letter to Augusto Righi, January 12, 1912, AXL, f. 87, 1. 332

17. Corbino, Orso Mario. Letter to Augusto Righi, January 26, 1912, AXL, f. 87, 1. 333

18. Corbino, Orso Mario. Letter to Augusto Righi, February 3, 1912, AXL, f. 87, 1. 334

19. Crawford, Elisabeth. 1984. The Beginnings of the Nobel Institution: The Sciences Prizes, 1901-1915. Cambridge University Press, Cambridge and Editions de la Maison des Sciences de l'Homme, Paris, p. 151

20. Dal telegrafo al telefono senza fili. Intervista con il prof. Augusto Righi, Il Resto del Carlino, January 9, 1903

21. Dam, H.J.W. 1897. The New Telegraphy. An Interview with Signor Marconi. Strand Magazine 13: 273-280

22. Dessau, Bernardo. 1970. L'opera scientifica di Augusto Righi. Giornale di Fisica 11: 61-73

23. Di Benedetto, Giovanni (ed). 1974. Bibliografia marconiana. Giunti, Firenze

24. Dragoni, Giorgio. 2016. RIGHI, Augusto, in Dizionario Biografico degli Italiani - Vol. 87. Treccani, Roma

25. Dragoni, Giorgio. 2017. Augusto Righi: Fisico e Matematico - una rilettura biografica. Quaderni di Storia della Fisica 19: $47-71$

26. Dragoni, Giorgio, Lodi, M. 2009. Marconi's Work: "Was it True Glory?". Il Nuovo Saggiatore 25(3-4): 57-68

27. Dragoni, Giorgio, Lodi, M., Garofalo, G. 2011. L'opera di Marconi. "Fu vera gloria?". Giornale di Fisica 52: 3-32

28. Dunlap, Orrin Elmer Dunlap. 1937. Marconi, the man and his wireless. Mac Millan, New York

29. Falciasecca, Gabriele and Valotti, Barbara. 2009. Guglielmo Marconi: the pioneer of wireless communications. 2009 European Microwave Conference (EuMC). IEEE, pp. 544-546

30. G. Il telegrafo senza fili del Marconi. Un'intervista col prof. Augusto Righi, Il Resto del Carlino, 28 maggio 1897

31. Gli esperimenti del telegrafo senza fili attraverso la Manica, La Domenica del Corriere, April 23, 1899

32. Guglielmo Marconi - Facts. NobelPrize.org. Nobel Media AB 2020. Mon. 7 Dec 2020. https://www.nobelprize.org/ prizes/physics/1909/marconi/facts/ 
33. Guillaume, Charles. Letter to Augusto Righi, March 15, 1900, AXL, f. 174, 1. 566

34. Hertz, Heinrich. 1888/1893. On electromagnetic waves in air and their reflections (English translation of original paper in Wiedemann's Annalen 34 (1888), p. 610), in Heinrich Hertz, Electric waves being researches on the propagation of electric action with finite velocity through space. MacMillan and Co., London, 1893, p. 124

35. Hildebrand, H. 1909/1967. Award ceremony speech, in Nobel Lectures, Physics 1901-1921. Elsevier Publishing Company, Amsterdam

36. Hong, Sungook. 1994. Marconi and the Maxwellians: The Origins of Wireless Telegraphy Revisited. Technology and Culture 35: 717-749

37. Hong, Sungook. 2001. Wireless: from Marconi's black-box to the Audion. MIT Press, Cambridge, Mass.

38. Ianniello, Maria Grazia (eds). 1995. Guglielmo Marconi. La telegrafia senza fili. Teknos, Roma

39. Il telegrafo senza fili. L'importante invenzione di un Bolognese. Il Resto del Carlino, December 22, 1896

40. Jolly, W.P. 1972. Marconi. Stein and Day, New York, 1972

41. Leone, Matteo and Robotti, Nadia. 2019. I Fisici Senatori: 1848-1943. Società Italiana di Fisica, Bologna

42. Leone, Matteo and Robotti, Nadia. 2020. Augusto Righi. Giornale di Fisica 61: 337-358

43. Lodge, Oliver and Howard, James. 1889. On electric radiation and its concentration by lenses. Phil Mag. 28: 48-65.

44. Lodge, Oliver. 1894. The Work of Hertz and some of his successors. Van Nostrand, New York

45. Lodge, Oliver. 1894. The Work of Hertz. Nature 50: 133-139

46. Lodge, Oliver. Letter to Augusto Righi, June 21, 1897, AXL, f. 209, 1. 680

47. Lodge, Oliver. 1897. Telegraphy without wires", The Times, June 22, 1897, p. 14

48. Lodge, Oliver. Letter to Augusto Righi, January 13, 1910, AXL, f. 209, 1. 690

49. Marconi, Guglielmo. 1896/1897. UK Patent No. 12039/96. Digitized version available here: http://www. alternativaverde.it/sttlcing/documenti/Marconi/1896/marc02061896a12,039.pdf

50. Marconi, Guglielmo. 1901. Syntonic wireless telegraphy. Journal of the Society of Arts 49: 506-517

51. Marconi, Guglielmo. 1902. The inventor of wireless telegraphy: a reply. The Saturday Review XCIII: 556-557

52. Marconi, Guglielmo. 1909/1967. Wireless telegraphic communication, in Nobel Lectures, Physics 1901-1921. Elsevier Publishing Company, Amsterdam

53. Marconi, Guglielmo. 1920. Notes. Nature 105: 526

54. Marconi, Guglielmo. Undated. Enclosure. Remarks on Mr. Orris E. Dunlap's Proofs, Archivio Guglielmo Marconi, Accademia dei Lincei, Rome, busta 3, fascicolo 135 - Dunlap Orrin Elmer Jr

55. Marconi e Augusto Righi. Il Resto del Carlino, October 8, 1902

56. Marconi Paresce, Degna. 1962. My father, Marconi. Muller, London

57. Our Book Shelf. La Telegrafia senza filo. 1903. Nature 67: 582-583

58. Pelosi, G., Selleri, S., Valotti, B. 2004. From Poldhu to the Italian Station of Coltano: Marconi and the First Years of Transcontinental Wireless. IEEE Antennas and Propagation Magazine 46(3): 47-54

59. Pesci, Ugo. 1903. Augusto Righi e la telegrafia senza filo. L'Illustrazione Italiana 30(9): 170-172

60. Popov, A. S. 1897. To the Editor. The Electrician 40: 235

61. Proposta della II Categoria della Classe di Scienze fisiche, matematiche e naturali di un premio Santoro, da conferirsi in via straordinaria e fuori concorso. 1902. Rendiconto dell'Adunanza Solenne del 1 giugno 1902, Atti della R. Accademia dei Lincei II: 49-50

62. Raboy, Marc. 2016. Marconi. The man who networked the world. Oxford University Press, New York

63. Radiocomunicazioni a grande e a grandissima distanza. Celebrazione nazionale del centenario della nascita di Guglielmo Marconi. 1976. Accademia Nazionale dei Lincei, Roma

64. Rava, Luigi. Letter to Augusto Righi, undated, AXL, f. 318, 1. 983

65. Regio decreto 10 luglio 1870, n. 5762 (Gazzetta Ufficiale del Regno d'Italia, n. 219, 11 agosto 1870)

66. Reif-Acherman, Simòn. 2013. Heike Kamerlingh Onnes and the Nobel Prize in Physics for 1913: The highest Honor for the Lowest Temperatures. Physics in Perspective 15: 415-450

67. Righi, Augusto. 1893. Su alcune disposizioni sperimentali per la dimostrazione e lo studio delle ondulazioni elettriche di Hertz. Rendiconti R. Acc. Lincei 1: 333-337

68. Righi, Augusto. 1894. Sulle oscillazioni elettriche a piccola lunghezza d'onda e sul loro impiego nella produzione di fenomeni analoghi ai principali fenomeni dell'ottica. Memorie Acc. Sci. Bologna 4: 487-591

69. Righi, Augusto. Extract from letter to Sir Oliver Lodge (June 18, 1897). George Francis Fitzgerald Collection, RDS, accessed December 9, 2020, https://digitalarchive.rds.ie/items/show/1337

70. Righi, Augusto. Letter to Oliver Lodge, June 25, 1897 (Lodge collection, University College, London, cited in Ian Inkster ed., History of Technology, Vol. 32. Bloomsbury, London 2014, p. 266)

71. Righi, Augusto. 1897. Il telegrafo senza fili. Gli apparecchi di cui si serve il Marconi, Il Resto del Carlino, 8 luglio 1897

72. Righi, Augusto. 1897. Nuovo indicatore di onde elettriche. Rendiconti R. Acc. Lincei 6: 245-246

73. Righi, Augusto. 1897. L'ottica delle oscillazioni elettriche. Zanichelli, Bologna

74. Righi, Augusto. 1898. Die Optik der elektrischen Schwingungen. Reisland, Leipzig

75. Righi, Augusto. Letter to Pietro Blaserna, undated (1901), AXL, f. 37, l. 177

76. Righi, Augusto and Dessau, Bernardo. 1903/1905. La telegrafia senza filo. Zanichelli, Bologna

77. Righi, Augusto and Dessau, Bernardo. 1903/1907. Die Telegraphie ohne Draht. Vieweg, Braunschweig

78. Righi, Augusto and Dessau, Bernardo. 1909. Telegrafía sin hilos. Imprenta de Ricardo Rojas, Madrid

79. Ròiti, Antonio. Letter to Augusto Righi, June 18, 1901, AXL, f. 330, 1. 1011 
80. Ròiti, Antonio. Letter to Augusto Righi, June 25, 1901, AXL, f. 330, 1. 1012

81. Ròiti, Antonio Ròiti, Blaserna, Pietro and Righi, Augusto. 1901. Relazione sul conferimento della medaglia Matteucci presentata dalla Commissione composta de' Soci Blaserna, Righi, Roiti, 30 giugno 1901, Accademia Nazionale delle Scienze detta dei XL, Premio Matteucci, b. 26, f. 01

82. Sarasin, Edouard and De La Rive, Auguste. 1892. Sur la production de l'étincelle de l'oscillateur de Hertz dans un diélectrique liquide, au lieu de l'air. Comptes rendus hebdomadaires des séances de l'Académie des sciences 115: 439-440

83. Signalling through space, The Times, June 7, 1897

84. Signalling through space without wires. 1897. Nature 56: 163-164

85. Signalling through space without wires. 1897. Science 6: 889-896

86. Sri Kantha, Sachi. 2012. Why Wright brothers failed to receive Nobel Prize recognition? Current Science 103: 435-437

87. Süsskind, Charles. 1962. Popov and the beginnings of radiotelegraphy. Proceedings of the Institute of Radio Engineers 50: 2036-2047

88. Süsskind, Charles. 1969a. The early history of electronics. III. Prehistory of radiotelegraphy. IEEE Spectrum 6(4): 69-74

89. Süsskind, Charles. 1969b. The early history of electronics. IV. First radiotelegraphy experiments. IEEE Spectrum 6(8): 66-70

90. The British Association. Section A - Mathematical and Physical Science. The Times, September 23, 1896, p. 8

91. Thompson, Silvanus P. Letter to Augusto Righi, January 31, 1897, AXL, fascicolo 388, lettera 1157

92. Thompson, Silvanus P. 1897. Telegraphy without wires, The Saturday Review LXXXIII: 708-709

93. Thompson, Silvanus P. 1902. The inventor of wireless telegraphy. The Saturday Review XCIII: 424-425

94. Thompson, Silvanus P. 1902. Wireless telegraphy: a rejoinder. The Saturday Review. XCIII: 598-599

95. Thompson, Silvanus P. Letter to Augusto Righi, June 14, 1902, AXL, f. 388, 1. 1158

96. Thompson, Silvanus P. Letter to Augusto Righi, July 5, 1902, AXL, f. 388, 1. 1159

97. Thompson, Silvanus P. Letter to Oliver Lodge, January 14, 1910, AXL, f. 388, l. 1163

98. Tommasina, Thomas. Letter to Augusto Righi, January 19, 1910, AXL, f. 393, 1. 1177

99. Valotti, Barbara. 1995. The Roots of Invention: New Sources on Young Marconi. Universitas 7: 1-5

100. Valotti, Barbara and Giorgi, Mario (eds). 2010. Guglielmo Marconi. Wireless Laureate. Bononia Univ. Press, Bologna

101. Vendik, Orest G. 1995. Popov, Marconi and radio. Nature 374: 672

102. Vicentini, Giuseppe. Letter to Augusto Righi, December 12, 1909 AXL, f. 416, 1. 1253 